\title{
Recovering Ex Ante Returns and Preferences for Occupations using Subjective Expectations Data*
}

\author{
Peter Arcidiacono ${ }^{\dagger} \quad$ V. Joseph Hotz ${ }^{\ddagger} \quad$ Arnaud Maurel $^{\S}$ \\ Teresa Romano
}

October 2014

\begin{abstract}
We show that data on subjective expectations, especially on outcomes from counterfactual choices and choice probabilities, are a powerful tool in recovering ex ante treatment effects as well as preferences for different treatments. In this paper we focus on the choice of occupation, and use elicited beliefs from a sample of male undergraduates at Duke University. By asking individuals about potential earnings associated with counterfactual choices of college majors and occupations, we can recover the distribution of the ex ante monetary returns to particular occupations, and how these returns vary across majors. We then propose a model of occupational choice which allows us to link subjective data on earnings and choice probabilities with the non-pecuniary preferences for each occupation. We find large differences in expected earnings across occupations, and substantial heterogeneity across individuals in the corresponding $e x$ ante returns. However, while sorting across occupations is partly driven by the ex ante monetary returns, non-monetary factors play a key role in this decision. Finally, our results point to the existence of sizable complementarities between college major and occupations, both in terms of earnings and non-monetary benefits.
\end{abstract}

${ }^{*}$ We thank seminar participants at the London School of Economics, Stanford University, University of Tennessee, and Washington University, as well as participants at the NBER Labor Studies 2014 Spring Meeting, the Workshop on Subjective Expectations and Probabilities in Economics and Psychology (Essex, March 2014), the 2014 European Meeting of the Econometric Society (Toulouse) and the 2014 Empirical Micro Jamboree (Duke) for helpful comments and suggestions. Luis Candelaria Barrera provided excellent research assistance.

${ }^{\dagger}$ Duke University and NBER.

${ }^{\ddagger}$ Duke University, NBER and IZA.

${ }^{\S}$ Duke University, NBER and IZA.

"Goucher College. 


\section{Introduction}

Subjective expectations data are increasingly being used in economic research. While early work focused on the accuracy of individual's forecasts over objective events (Manski, 1993, 2004; Hurd and McGarry, 1995, 2002; Dominitz and Manski, 1996, 1997), ${ }^{1}$ more recent work has used such forecasts in the estimation of structural dynamic models (Delavande, 2008; van der Klaauw and Wolpin, 2008; van der Klaauw, 2012). Using agents' subjective expectations requires fewer assumptions about how individuals form their beliefs about future outcomes than is typically required to estimate such forward-looking models.

Relatively new to the literature is the elicitation of: (i) probabilities of taking particular courses of actions in the future and (ii) expectations about potential future outcomes corresponding to counterfactual choices (or treatments) that are off the individual's actual choice path. We show that capturing future choice probabilities as well as expectations both on and off the individual's choice path can be a powerful tool in recovering treatments effects as well as the non-pecuniary benefits associated with different treatments. ${ }^{2}$

While the proposed approach can be applied to a broad class of potential outcomes models, in this paper we consider the role played by the expected, or ex ante, monetary returns and non-pecuniary preferences in the choice of occupations for different college majors. As recently emphasized in a series of papers on schooling decisions in the presence of heterogeneity and uncertainty (see, e.g., Carneiro et al., 2003; Cunha et al., 2005; Cunha and Heckman, 2007 and Cunha and Heckman, 2008), agents' decisions are based on ex ante monetary returns, as opposed to ex post ones. Complementing this literature, we use data that directly elicits agents' ex ante returns, thus allowing us to remain agnostic about how agents form their information sets. By using subjective expectations data on occupations for all counterfactual majors, we are able to identify the separate influence of monetary returns vs. non-pecuniary factors in the absence of exclusion restrictions. ${ }^{3}$

There is substantial heterogeneity in earnings across majors and occupations. For instance, data from the American Community Survey (2009-2010) reveal that those who ma-

\footnotetext{
${ }^{1}$ See Manski (2004) and Hurd (2009) for surveys of measuring and using subjective expectations in economics.

${ }^{2}$ Related papers by Blass et al. (2010), Reuben et al. (2013), and Delavande and Zafar (2014) employ elicited data on choice probabilities and expectations about counterfactual choices to estimate dynamic structural models. Pantano and Zheng (2013) show how subjective expectations data about agents' future choices can be used to recover unobserved heterogeneity in dynamic structural models.

${ }^{3}$ D'Haultfoeuille and Maurel (2013) investigate the relative importance of ex ante monetary returns versus non-pecuniary factors in the decision to attend college. Their approach, which can be used in the absence of subjective expectations data, does not require exclusion restrictions but does require imposing stronger assumptions on the non-pecuniary factors. See also Eisenhauer et al. (2014), who use exclusion restrictions between monetary returns and non-pecuniary factors to separately identify these two components.
} 
jored in engineering earn as much as $77 \%$ more than those who majored in the humanities. To the extent that a sizable fraction of college graduates work in an occupation which does not match their major, those earnings differentials across majors mask the existence of substantial within-major dispersion. ${ }^{4}$ For instance, Kinsler and Pavan (2014) estimate that there is a $30 \%$ premium for STEM college graduates who work in an occupation related to their major. While these earnings differentials are based on individuals who chose particular majors and occupations and, as such, are not causal, they clearly suggest that occupational choice is a key economic decision, even after conditioning on college major. Occupations also differ in a number of other, non-wage, dimensions. Preferences for these non-wage characteristics are likely to be heterogeneous, in particular with respect to the chosen college major.

We use elicited beliefs from male undergraduates at Duke University to recover the distribution of ex ante monetary returns to different occupations and to quantify the importance of sorting across occupations on ex ante monetary returns versus preferences. This unique dataset contains student expectations regarding the probability of working in different occupations as well as their expected income in each of the occupations where the period of reference is ten years after they graduate. ${ }^{5}$ Importantly, these occupation probabilities and expected incomes were asked not only for the major the individual chose but also for counterfactual majors, making it possible to disentangle both the monetary returns from different majors in different occupations as well as how attractive working in particular occupations is with different majors. By doing so, we add to a growing set of papers using subjective expectations data to distinguish between the role played by monetary returns versus nonpecuniary preferences in individual decisions. While several papers have recently addressed this question in the related context of college major and university choices (see, e.g., Zafar, 2011, 2013; Arcidiacono et al., 2012; Delavande and Zafar, 2014; Long et al., 2014; Stinebrickner and Stinebrickner, 2014 and Wiswall and Zafar, 2014), our paper is, to the best of our knowledge, the first to do so in the context of occupational choices. ${ }^{6}$

The data allow us to identify both the ex ante treatment effects of particular occupations (relative to a reference occupation) on earnings, for any given college major, as well as the

\footnotetext{
${ }^{4}$ See Altonji et al. (2012) for a recent review of the literature on college major and occupational choices.

${ }^{5}$ This dataset was previously used to examine the determinants of college major choice by Arcidiacono et al. (2012). Their paper treated occupations as lotteries, where the lotteries were affected by the choice of major. In this paper, we follow a more conventional route and treat occupations as choices, consistent with, e.g., Miller (1984), Siow (1984), Keane and Wolpin (1997), Antonovics and Golan (2012) and van der Klaauw (2012).

${ }^{6}$ Related work by Osman (2014) uses subjective expectations data to investigate the determinants of the decision to become self-employed, to engage in wage work or to stay out of the labor force in a population of Egyptian students graduating from a vocational high school.
} 
ex ante treatment effects of particular majors on the probabilities of working in any given occupation. Even though we do not observe the actual occupations chosen by the individuals, we show that data on occupational choice subjective probabilities can be used to recover the ex ante treatment effects of a given occupation for the subpopulation of individuals who will end up working in that occupation (ex ante treatment effect on the treated). Taking the initial major as given, the ex ante treatment effect on the treated for a given occupation $j$ is estimated by weighting the reported earnings differences between occupation $j$ and the reference by the probability the individual reports that he will work in occupation $j$ (over the average declared probability of working in that occupation). Ex ante treatment effect on the untreated are obtained similarly, by using instead the declared probability that the individual will not work in occupation $j$. Importantly, our data allows us to go beyond these average effects and investigate the heterogeneity across individuals by estimating the full distributions of the ex ante treatment effects of working in any given occupation $j$ relative to education. Data on occupational choice probabilities further allows us to recover the distribution of the ex ante treatment effects within the treated and untreated subpopulations.

The results reveal substantial differences in expected earnings across occupations. Treating the education occupation as the baseline, the average ex ante return range from $31 \%$ higher earnings (science) to as much as 124\% higher earnings (business) ten years after graduation. The ex ante returns are higher for the treated than for the untreated, suggesting positive selection into occupations based on the monetary returns. We also document the existence of a large degree of heterogeneity in the ex ante returns for each occupation across college majors, consistent with the accumulation of occupation-specific human capital within each major. For example, natural science majors anticipate a premium for a health career (relative to education) that is more than 5 times larger than the premium that public policy majors anticipate for the same occupation.

We next propose a model of occupational choice where individuals are uncertain over their preferences for particular occupations in the future. This simple framework allows us to link the subjective data on expected earnings and choice probabilities with the non-pecuniary preferences for each occupation. Under standard assumptions, unobserved preferences will have continuous support over the real line, implying that perceived occupation probabilities should be bounded away from zero and one. However, in our sample, a sizable fraction of individuals do report zero probabilities of pursuing a particular occupation, conditional on a particular major. To reconcile our conceptual framework with the elicited choice probabilities, we assume that the resolution of preference uncertainty is costly to agents. That is, we suppose that individuals must bear a cost to acquire additional information about a given occupation, and that they will only do so if the expected benefits of doing so are 
sufficiently high. In estimation, we then follow Hotz and Miller (1993) and Berry (1994) and invert the perceived choice probabilities, taking into account the selection introduced by costly information acquisition, to recover labor supply elasticities for each occupation and preferences over occupation-major combinations.

Our empirical model of agents' valuations of occupations - which depend, in part, on the expected incomes elicited for each occupation - allows us to estimate the labor supply elasticities for each occupation, along with the aggregate preferences over the different occupation-major combinations and the heterogeneity in preferences for each occupation. While we find significant and sizable earnings elasticities of occupational choice, our estimates reveal that non-wage factors play a key role in the choice of occupation. In particular, our results are consistent with the existence of large willingnesses-to-pay for non-wage characteristics of the occupation-major combinations. For instance, an economics major would need to make more than three times as much in education to be indifferent between education and business. ${ }^{7}$

The rest of the paper proceeds as follows. In Section 2, we discuss the survey data used in the paper. Section 3 shows how to obtain ex ante treatment effects given the data, and then discuss the estimated treatment effects. We then link the subjective occupational choice probabilities and expected incomes with a model of occupational choice in Section 4. In Section 5, we discuss the estimation results of the occupational choice model and the possible role that factors like differences in occupation-specific job offer arrival rates by college majors might play in accounting for the large willingnesses-to-pay for the non-wage components. Finally, we offer some concluding comments in Section 6.

\section{Data}

We use data from the Duke College Major and Expectations Survey (DuCMES) that was collected on a sample of male undergraduate students at Duke University between February and April 2009. ${ }^{8}$ Gender was the only restriction on sample recruitment; male students from any major, class, or race were eligible to participate in the survey. Sample members were recruited by posting flyers around the Duke campus. Surveys were administered on computers in a designated room in Duke's Student Union. All 173 students who completed

${ }^{7}$ As we discuss in Section 5 , the large differences in willingness-to-pay for non-wage features of occupations could also arise from differences in job arrival rates among the different major-occupation combinations. Regardless of the mechanism, our results provide clear evidence that majors have a substantial influence on occupations well beyond their impact on earnings.

8 Arcidiacono et al. (2012) also use the DuCMES data employed in this paper. We refer the reader to that paper for a more comprehensive overview of the data. 
the survey were paid $\$ 20 .^{9}$

The DuCMES collected information on students' background characteristics and their current or intended major. ${ }^{10}$ Table 1 presents a descriptive overview of our sample. The composition of our sample corresponds fairly closely to the Duke male undergraduate student body. The sample includes slightly more Asians and fewer Latinos and Blacks than in the Duke male student body, and it overrepresents students in Science majors while underrepresenting students in Public Policy. ${ }^{11}$ It also appears that a higher percentage of the sample receives some financial aid than is the case in the Duke student body, although the $22.0 \%$ figure for the student body is based on aid provided by Duke, whereas the higher percentage of students receiving financial aid $(40.5 \%)$ is likely due in part to the fact that our survey asked about receipt of financial aid, regardless of source. Finally, we note that the sample is slightly tilted towards upper-classmen.

The DuCMES elicited from the students their expectations about their likelihood of choosing future careers and how much they expected to earn in them. Specifically, for each of the six majors groups displayed in the Table 1, we asked students the probability that they would enter a particular career and the earnings they would expect to receive in that career 10 years after graduation. We used the following six broad career groups to characterize possible careers: Science/Technology, Health, Business, Government/Non-Profit, Education and Law. It is important to note that for all students in the sample, those probabilities and expected earnings are elicited for all possible occupation-major combinations, i.e. both for the chosen (or intended) majors and the counterfactual majors.

Table 2 reports the mean expected incomes for the various major-occupation combinations. ${ }^{12}$ Expected incomes exhibit sizable variation both across majors and occupations. For instance, majoring in science or engineering is perceived to lead to higher earnings in science and health careers, while expected earnings in business are on average higher for economics

\footnotetext{
${ }^{9}$ We drop from our analysis five individuals who reported that they would choose one occupation with certainty for each major, resulting in a final sample of 168 students.

${ }^{10} \mathrm{In}$ most of the paper we refer for simplicity to the current or intended major as the chosen major. A copy of the questionnaire used in the survey can be found at www.econ.duke.edu/ vjh3/working_papers/college_major_questionnaire.pdf and is discussed further in Kang (2009).

11 The mapping of students' actual college majors into the major groups displayed in Table 1 are found in the Appendix to Arcidiacono et al. (2012).

${ }^{12}$ In our sample, only $1.6 \%$ of the expected earnings are missing. For these cases, expected earnings, for each major and occupation, are set equal to the predicted earnings computed from a linear regression of log-earnings on major and occupation indicators, interaction between major and occupation, individualspecific average log-earnings across all occupations and majors and an indicator for whether the subjective probability of working in this occupation is equal to zero. One individual in our sample declared that he expected to earn $\$ 1,000$ for some occupation-major combinations. We assume that this individual declared monthly rather than yearly incomes, and rescale his expected income accordingly.
} 
Table 1: Sample Descriptive Statistics

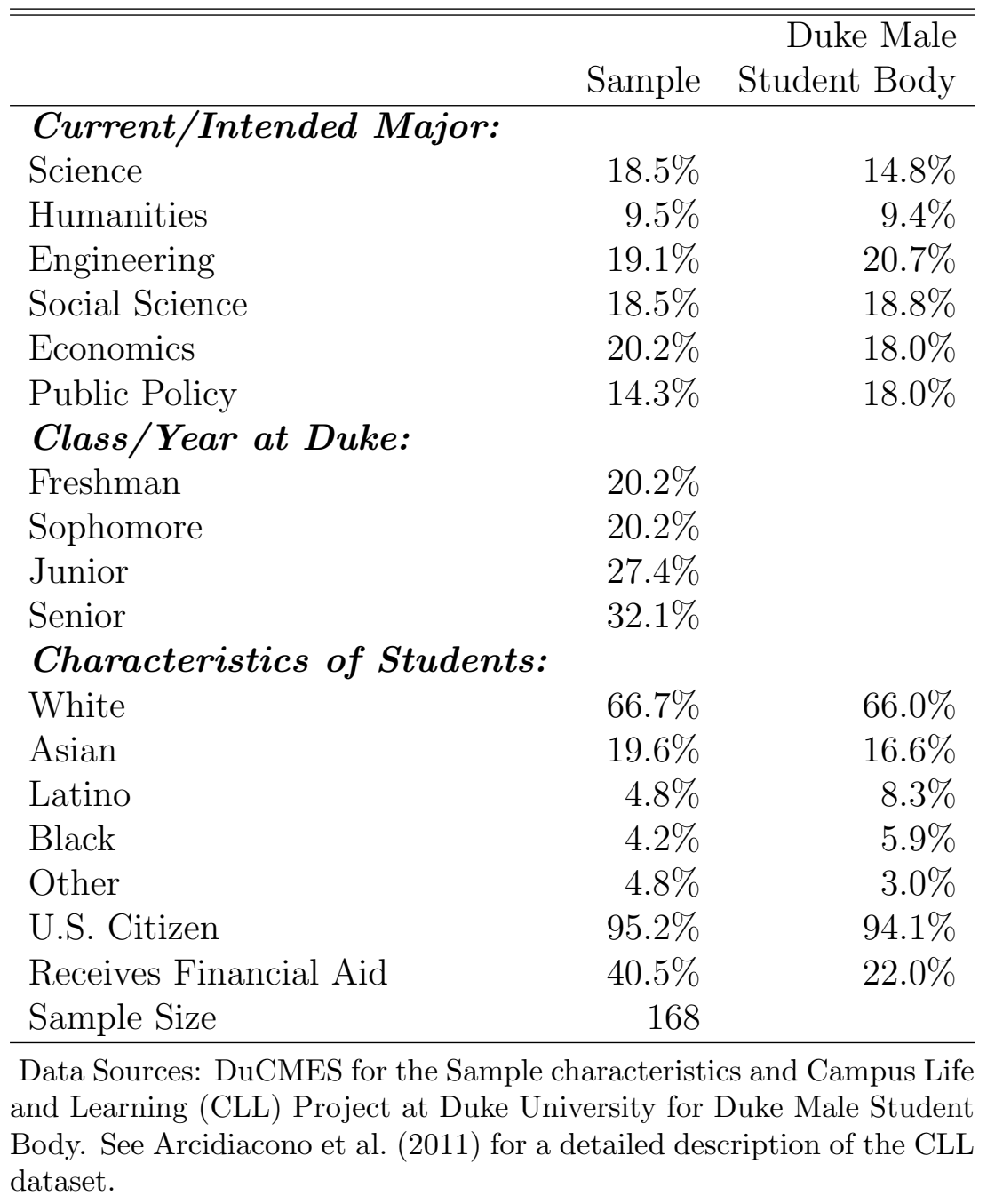


Table 2: Mean expected incomes for different major/occupation combinations (Annual Incomes, in dollars)

\begin{tabular}{lrrrrrr}
\hline \hline & & \multicolumn{6}{c}{ Occupation: } \\
Major: & Science & Health & Business & Government & Education & Law \\
\hline Science & 109,170 & 164,020 & 139,760 & 95,130 & 72,850 & 146,230 \\
Humanities & 81,820 & 127,040 & 131,410 & 91,510 & 71,120 & 149,580 \\
Engineering & 119,500 & 155,080 & 155,040 & 98,360 & 75,530 & 168,860 \\
Social Sciences & 85,750 & 126,840 & 146,510 & 96,260 & 71,200 & 152,030 \\
Economics & 90,400 & 132,130 & 200,230 & 102,880 & 78,720 & 161,400 \\
Public Policy & 89,490 & 126,780 & 158,070 & 110,500 & 72,160 & 166,880 \\
\hline
\end{tabular}

Note: Major can either be the chosen major or a counterfactual major so each cell contains the average of 168 observations.

majors. Differences across occupations are even starker. In particular, average expected incomes are lowest for a career in education and generally highest for a career in law, with the exception of science and economics majors for which expected incomes are highest for health and business occupations, respectively.

Table 3 presents the average subjective probabilities of working in each occupation that were elicited from students who were asked to condition on having majored in each of the various subject areas. The subjective probabilities of entering each occupation vary substantially across majors. It is worth noting that none of the majors are concentrated into one, or even two, occupations. For any given major, the average subjective probabilities are larger than $10 \%$ for at least three occupations. Even for majors which appear to be more tied to a specific occupation, such as Business for Economics majors, the corresponding subjective probabilities exhibit a fairly large dispersion across individuals (see Figure 1). Overall, the likelihood of working in the various occupations appear to be selectively different across individuals, even after conditioning on a college major. ${ }^{13}$

Table 4 reports the prevalence of zero probability reported by students, for each majoroccupation combination. ${ }^{14}$ While some combinations display a large share of zero subjective probabilities, the shares stay well away from one, suggesting that particular majors do not rule out certain occupations for all individuals.

\footnotetext{
${ }^{13}$ Results for other combinations of occupations and majors are not reported here to save space, but are available from the authors upon request.

${ }^{14}$ The survey design was such that the default values of the subjective probabilities were set equal to zero for all occupation-major combinations. As a result, it might be that some of the zero probabilities observed in the data reflect missing probabilities rather than true zeros. However, in the former case, it seems likely that the latent (unobserved) probabilities are typically close to zero, so that aggregating these two types of zero probabilities should not be too much of a concern.
} 
Table 3: Mean elicited probabilities of choosing alternative occupations, conditional on majoring in alternative fields

\begin{tabular}{lrrrrrr}
\hline \hline & & \multicolumn{6}{c}{ Occupation: } \\
Major: & Science & Health & Business & Government & Education & Law \\
\hline Science & 0.345 & 0.323 & 0.124 & 0.072 & 0.071 & 0.066 \\
Humanities & 0.076 & 0.121 & 0.230 & 0.149 & 0.231 & 0.194 \\
Engineering & 0.399 & 0.200 & 0.191 & 0.076 & 0.069 & 0.065 \\
Social Sciences & 0.095 & 0.145 & 0.246 & 0.192 & 0.131 & 0.191 \\
Economics & 0.058 & 0.078 & 0.512 & 0.159 & 0.064 & 0.129 \\
Public Policy & 0.055 & 0.116 & 0.229 & 0.320 & 0.077 & 0.203 \\
\hline
\end{tabular}

Note: Major can either be the chosen major or a counterfactual major so each cell contains the average of 168 observations.

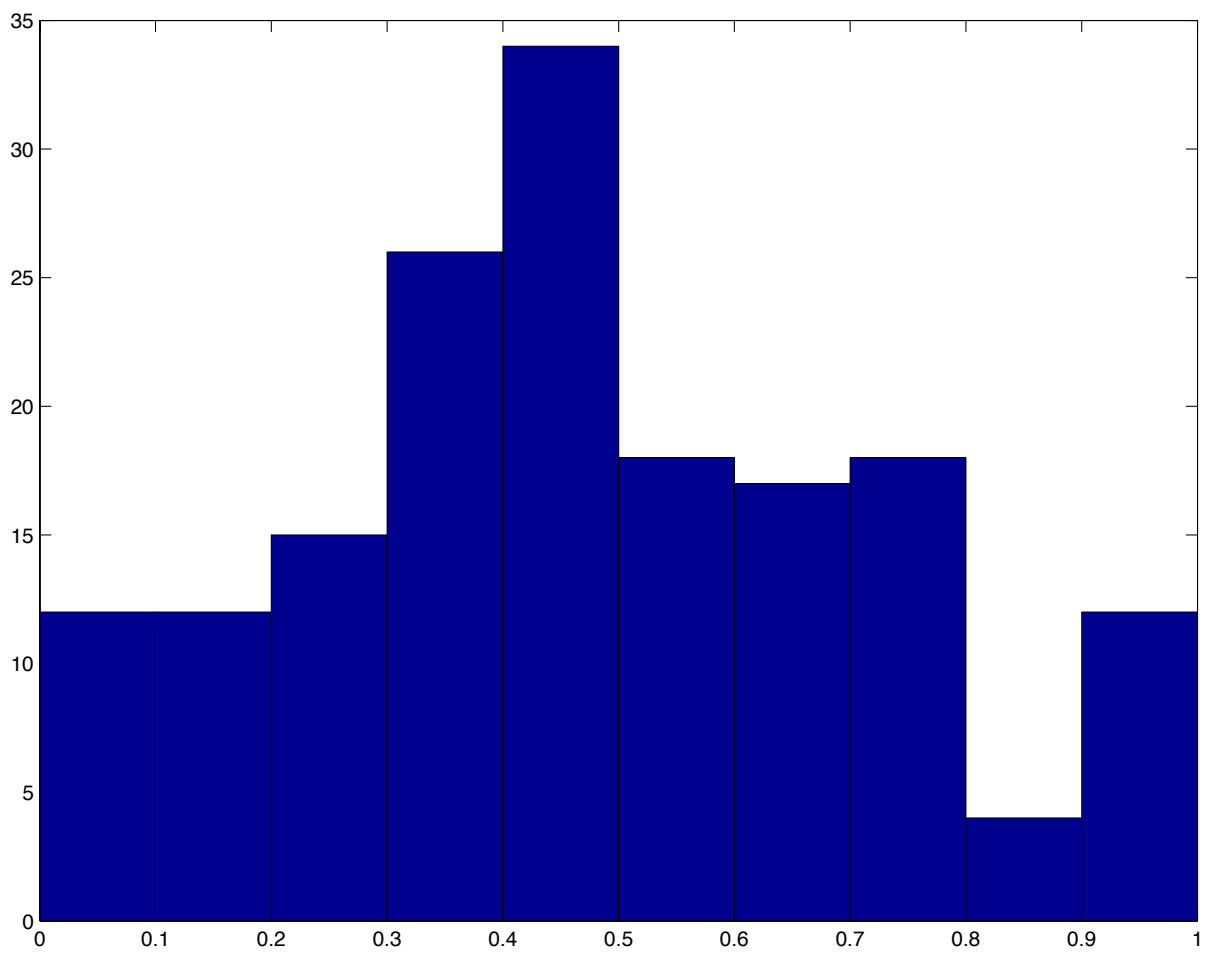

Figure 1: Frequency distribution of subjective probabilities (economics major, business occupation) 
Table 4: Incidence of elicited zero probabilities of choosing occupations, conditional on majoring in alternative fields

\begin{tabular}{lrrrrrr}
\hline \hline & & \multicolumn{5}{c}{ Occupation: } \\
Major: & Science & Health & Business & Government & Education & Law \\
\hline Science & $3.57 \%$ & $7.14 \%$ & $27.98 \%$ & $35.50 \%$ & $39.29 \%$ & $43.45 \%$ \\
Humanities & $48.81 \%$ & $34.52 \%$ & $13.69 \%$ & $18.45 \%$ & $17.26 \%$ & $16.67 \%$ \\
Engineering & $7.14 \%$ & $22.02 \%$ & $20.83 \%$ & $45.24 \%$ & $47.02 \%$ & $50.60 \%$ \\
Social Sciences & $45.24 \%$ & $30.95 \%$ & $10.12 \%$ & $13.10 \%$ & $25.00 \%$ & $17.86 \%$ \\
Economics & $53.57 \%$ & $49.40 \%$ & $2.38 \%$ & $17.26 \%$ & $45.24 \%$ & $28.57 \%$ \\
Public Policy & $55.36 \%$ & $36.31 \%$ & $13.10 \%$ & $3.57 \%$ & $38.69 \%$ & $11.90 \%$ \\
\hline
\end{tabular}

Note: Major can either be the chosen major or a counterfactual major so each cell contains the average of 168 observations.

Since it is important for the rest of our analysis that the elicited expectations, in particular over future incomes, reflect actual beliefs, we attempt to assess how reasonable they are by comparing them with data form the American Community Survey (ACS). From this set of comparisons, we can see where Duke students believe they rank relative to the population of college graduates who actually chose particular major-occupation combinations. We utilize data on wages, college major and current occupation from the 2009-2011 ACS. We limit the ACS sample to males between the ages of 29 and 35, with a reported major field for their college degree. ${ }^{15}$ Majors in the ACS were categorized similarly to the Duke data. Several majors in the ACS are not offered at Duke; to the extent they clearly fell into one of the six major categories, they were included in that category. ${ }^{16}$ Occupations were constructed by matching the occupations categories in the ACS with the occupation groupings in the Duke data. ${ }^{17}$

To compare the ACS earnings to the expected earnings from the DuCMES data, we estimated the following regression using the ACS sample:

$$
\ln \left(w_{i j k}\right)=\alpha_{j k}+\beta_{k} a g e_{i}+\nu_{i j k},
$$

where $w_{i j k}$ is the annual earnings of person $i$ with major $j$ and occupation $k$ and $\nu_{i j k}$ is an unobserved idiosyncratic shock, $\alpha_{j k}$ is a vector of dummy variables for each major $j$ occupation $k$ pair and age effects $\left(\beta_{k}\right)$ are allowed to differ across occupations. The results of this regression were then used to estimate the distributions of log-earnings at age 32 for

\footnotetext{
${ }^{15}$ The Duke respondents, on average, would be of age 32 ten years after graduation.

${ }^{16}$ Most of the excluded majors were health services majors and vocational majors such as construction services.

${ }^{17}$ Science, computing, and engineering occupations were coded as science and technology careers; medicine was coded as health careers; business and finance was coded as business career; legal was coded as law careers and nonprofit occupations as well as local, state or federal occupations were coded as government/nonprofit.
} 
Table 5: Percentile of distribution of earnings from the American Community Survey (ACS) where median of Duke students' elicited expected earnings falls, conditional on chosen major

\begin{tabular}{lrrrrrr}
\hline \hline & & \multicolumn{5}{c}{ Occupation: } \\
Major: & Science & Health & Business & Government & Education & Law \\
\hline Science & $87.61 \%$ & $91.33 \%$ & $93.33 \%$ & $90.06 \%$ & $87.07 \%$ & $79.26 \%$ \\
Humanities & $80.06 \%$ & $90.31 \%$ & $82.44 \%$ & $83.58 \%$ & $78.79 \%$ & $68.25 \%$ \\
Engineering & $58.08 \%$ & $91.82 \%$ & $68.29 \%$ & $69.01 \%$ & $76.03 \%$ & $55.76 \%$ \\
Social Sciences & $91.24 \%$ & $94.82 \%$ & $98.37 \%$ & $86.68 \%$ & $78.79 \%$ & $56.29 \%$ \\
Economics & $72.45 \%$ & $93.68 \%$ & $73.33 \%$ & $70.23 \%$ & $52.05 \%$ & $79.46 \%$ \\
Public Policy & $73.86 \%$ & $85.52 \%$ & $87.01 \%$ & $70.58 \%$ & $73.94 \%$ & $78.40 \%$ \\
\hline
\end{tabular}

each occupation-major combination, enabling the comparison of the ACS labor earnings with the distributions of expected earnings of the Duke students in our sample.

In Table 5, we present the percentile of the distribution of predicted ACS earnings at which the median Duke student who chose major $j$ would fall based on their elicited expected earnings in each occupation. The percentiles are all above 50\% but generally below $90 \%$, with most entries in the seventies and eighties. These numbers seem reasonable given that Duke is a highly selective institution, generally ranked in the top 10 according to U.S. News \&6 World Report.

Finally, we provide some preliminary evidence about the role played by expected earnings in the choice of occupation by presenting in Table 6 students' expected earnings associated with each of the possible majors under two different scenarios about occupations. In the first ("Reported Probabilities"), expected earnings are based on the weighted average of elicited earnings for the different occupations, where the weights are the individual subjective probabilities of working in each occupation that were elicited from students. In the second ("Random Assignment"), we weight instead by the average subjective probability of choosing each occupation conditional on major.

Comparing the first two columns (see column labeled "Difference"), we find that students' expected earnings are higher using their reported probabilities of sorting into occupations relative to the case where the weights are the average probabilities of each occupation conditional on major. This pattern provides evidence of sizable monetary gains to sorting, consistent with the individuals pursuing their comparative advantage when choosing an occupation. $^{18}$

\footnotetext{
${ }^{18}$ Since we are using subjective data, one might be concerned that these gains to sorting are partly driven by ex post rationalization. However, our respondents are college students and we suspect most of them had not chosen an occupation at the time of our survey. This is confirmed by the fact that the share of subjective probabilities larger than $80 \%$ is less than $5 \%$ for $90 \%$ of the respondents, suggesting that the vast majority of these students were not yet committed to a particular occupation.
} 
Table 6: Expected Earnings (Annual Earnings, in dollars)

\begin{tabular}{lrrr}
\hline \hline & \multicolumn{3}{c}{ Calculated using: } \\
Reported & $\begin{array}{r}\text { Random } \\
\text { Probabilities }\end{array}$ & \\
Assignment & Difference \\
\hline Najor & 169,385 & 144,710 & 24,675 \\
Public Policy & 184,992 & 156,058 & 28,934 \\
Humanities & 115,786 & 108,928 & 6,858 \\
Economics & 160,488 & 134,941 & 25,547 \\
Engineering & 123,898 & 117,056 & 6,842 \\
Social Sciences & 136,223 & 118,098 & 18,125 \\
\hline
\end{tabular}

Note: Major can either be the chosen major or a counterfactual major so each cell contains the average of 168 observations. Weights in column 2 are taken from the student's subjective reports for each occupation conditional on the major in column 1 . Weights in column 3 are taken from the average subjective reports for the occupation, again conditional on the major in column 1.

\section{$3 \quad$ Ex ante treatment effects}

In this section we outline the different types of ex ante treatment effects we are interested in can be measured and show the corresponding effects in our data. We begin by considering standard treatment effect measures such as the average treatment effect, the average treatment on the treated, and the average treatment on the untreated. We then show how to calculate the full distribution of the various treatment effects and report examples from certain occupations. Finally, we consider treatment effects conditional on different choices of major.

\subsection{Average treatment effects}

We define the ex ante treatment effects of working in particular occupations on earnings relative to pursuing a career in Education, which serves as our baseline occupation and is labeled as occupation $k=1 .{ }^{19}$ For any given individual $i$, the ex ante treatment effect of occupation $k \in\{2,3,4,5,6\}$, conditional on majoring (or intending to major) in field $j$, is simply given by $w_{i j k}-w_{i j 1}$ where $w_{i j k}$ is individual $i$ 's expected earnings in occupation $k$ given major $j$. These ex ante treatment effects are directly observed in our data. The

\footnotetext{
${ }^{19} \mathrm{We}$ choose to use education as a baseline because the earnings in this occupation do not vary much across college majors (see Table 2), thus making it easier to interpret the heterogeneity across majors in the ex ante treatment effects.
} 
average ex ante treatment effect of occupation $k$, denoted by $A T E(k)$, is then defined by:

$$
A T E(k):=E\left(\sum_{j} I\left(d_{i}=j\right)\left[w_{i j k}-w_{i j 1}\right]\right)
$$

where $I\left(d_{i}=j\right)$ is an indicator for whether $i$ chose (or intends to choose) major $j$. This population parameter is estimated using its sample analog:

$$
\widehat{\operatorname{ATE}(k)}:=\frac{\sum_{i} \sum_{j} I\left(d_{i}=j\right)\left[w_{i j k}-w_{i j 1}\right]}{N},
$$

where $N$ is the sample size.

Similarly, we estimate the ex ante treatment effect of occupation $k$ on the treated by weighting the differences in the reported earnings between occupation $k$ and the baseline occupation by the probability the individual reports that he will work in occupation $k 10$ years after graduation (over the sum of declared probabilities of working in occupation $k$ ). That is:

$$
\widehat{T T(k)}:=\frac{\sum_{i} \sum_{j} I\left(d_{i}=j\right) p_{i j k}\left[w_{i j k}-w_{i j 1}\right]}{\sum_{i} \sum_{j} I\left(d_{i}=j\right) p_{i j k}},
$$

where $p_{i j k}$ is the elicited probability from individual $i$ that he would choose occupation $k$ given major $j$.

Finally, the ex ante treatment effect of occupation $k$ on the untreated is estimated by:

$$
\widehat{\operatorname{TUT}(k)}:=\frac{\sum_{i} \sum_{j} I\left(d_{i}=j\right)\left(1-p_{i j k}\right)\left[w_{i j k}-w_{i j 1}\right]}{\sum_{i} \sum_{j} I\left(d_{i}=j\right)\left(1-p_{i j k}\right)} .
$$

The estimated effects, $\widehat{A T E(k}), \widehat{T T(k)}$ and $\widehat{T U T(k)}$, defined in (3.2), (3.3), and (3.4), respectively, are not based on actual occupational choices, since these students have not yet chosen an occupation. Rather, we use students' elicited probabilities of choosing the various occupations to characterize these choices.

Table 7 presents estimates of the three ex ante treatment effects of working in particular occupations on earnings 10 years after graduation which correspond to the estimators defined earlier in (3.2)-(3.4). Relative to Education, the average ex ante treatment effects range from $\$ 22,541$ for Science (30.6\% of the mean expected earnings in Education) to as much as $\$ 91,181$ in Business (123.9\% of the mean expected earnings in Education). Health, Business and Law careers all have very large earnings premia of over $94 \%$, while those working in a Science or Government occupation expect a much smaller premium of $30.6 \%$ to $35.7 \%$ ten years after graduation. Consistent with positive sorting across occupations, our estimates 
Table 7: Ex Ante Treatment Effects of Occupations (Annual Earnings, in dollars)

\begin{tabular}{lrrrr}
\hline \hline Occupation & TT & TUT & ATE & $\begin{array}{r}\text { ATE: share of } \\
\text { Education earnings }\end{array}$ \\
\hline Science & 30,040 & 20,901 & 22,541 & $30.6 \%$ \\
\multirow{3}{*}{ Health } & $(4,446)$ & $(3,017)$ & $(2,952)$ & \\
& 117,770 & 59,239 & 69,555 & $94.5 \%$ \\
Business & $(14,647)$ & $(5,498)$ & $(6,217)$ & \\
\multirow{3}{*}{ Government } & 106,600 & 85,530 & 91,181 & $123.9 \%$ \\
\multirow{2}{*}{ Law } & $(10,494)$ & $(8,550)$ & $(8,261)$ & \\
& 26,740 & 26,214 & 26,281 & $35.7 \%$ \\
& $(6,025)$ & $(4,668)$ & $(4,583)$ & \\
& 116,590 & 85,159 & 90,066 & $122.4 \%$ \\
\hline
\end{tabular}

Note: Standard errors are reported in parentheses.

show that, for each occupation, the untreated anticipate lower premia than the treated. The difference is particularly large for Health occupations, where the expected premium is almost two times smaller for the untreated. These sorting effects turn out to be much weaker for Science careers, where the untreated anticipate to earn $70 \%$ as much as the treated, and are negligible for Government careers.

\subsection{Full distribution of treatment effects}

Importantly, our data allows us to generate not only average effects, but also estimate the distributions of the ex ante treatment effects of working in any given occupation $k$, relative to the baseline occupation. We estimate the distributions of the ex ante treatment effects, conditional on students' initial college major choice, for three different subgroups of interest, namely (i) the overall population, (ii) the treated subpopulation, and (iii) the untreated subpopulation. We briefly sketch below the steps involved in their estimation.

First, the density of the distribution of the ex ante treatment effects on the overall population can be simply estimated with a kernel density estimator, using the fact that we have direct measures of the ex ante treatment effects for each occupation $k, k=2, \ldots, 6$, for each student in our sample. We denote the resulting density by $f_{T E, k}(\cdot)$ and its estimator by $\widehat{f_{T E, k}(\cdot)}$.

Second, it follows from Bayes' rule that we can estimate the density of the distribution of the ex ante treatment effects on the treated subpopulation, denoted by $f_{T E, k}^{\text {Treated }}(\cdot)$, as follows, 
for any scalar $u$ :

$$
\widehat{f_{T E, k}^{T r e a t e d}}(u):=\frac{\widehat{f_{T E, k}(u)} \times \hat{g}(u)}{1 / N \times \sum_{i} \sum_{j} I\left(d_{i}=j\right) p_{i j k}} .
$$

where $g(u):=E\left(\sum_{j} I\left(d_{i}=j\right) p_{i j k} \mid w_{i j k}-w_{i j 1}=u\right)$ and $\hat{g}(u)$ denotes a consistent estimator of $g(u)$ (e.g. Nadaraya-Watson estimator).

Finally, we note that the distribution of the ex ante treatment effects on the untreated can be estimated by replacing $p_{i j k}$ with $\left(1-p_{i j k}\right)$ in $(3.5)$.

Figures 2, 3, and 4 plot the densities of the ex ante treatment on the treated and treatment on the untreated for Government, Health, and Business occupations, respectively. ${ }^{20}$ Each of the figures shows a different pattern of selection. For Government, the distributions for the treated and the untreated are essentially the same: there is little role for selection into Government jobs, at least relative to Education. For Health, the treated distribution is to the right of the untreated distribution, suggesting substantial positive selection. For Business careers, while there appears to be significant selection at the bottom end of the distribution, the discrepancy between the two distributions is attenuated in the top end. This latter pattern suggests that there is a significant group of individuals who would do quite well in business - essentially as well as the highest returns individuals from the treated group - but whose preferences, or expected earnings in other occupations, lead them away from business. Overall, these results suggest that there is much more to the distributions of ex ante treatment effects than just their means.

\subsection{Average treatment effects conditional on major}

While $\widehat{T T(k)}, \widehat{T U T(k)}$ and $\widehat{A T E(k)}$ are obtained by averaging over different choices of college major, we also can estimate the ex ante treatment effects of occupations conditional on each of the particular majors. Namely, we estimate the average ex ante treatment effect, ex ante treatment on the treated and treatment on the untreated for each chosen major $j$ by:

$$
\begin{gathered}
\widehat{A T E(k \mid} j):=\frac{\sum_{i} I\left(d_{i}=j\right)\left[w_{i j k}-w_{i j 1}\right]}{\sum_{i} I\left(d_{i}=j\right)} \\
\widehat{T T(k \mid j)}:=\frac{\sum_{i} I\left(d_{i}=j\right) p_{i j k}\left[w_{i j k}-w_{i j 1}\right]}{\sum_{i} I\left(d_{i}=j\right) p_{i j k}}
\end{gathered}
$$

\footnotetext{
${ }^{20}$ All densities were estimated using 100 grid points over the support, and a Gaussian kernel with optimal default bandwidth returned by the procedure ksdensity in Matlab.
} 


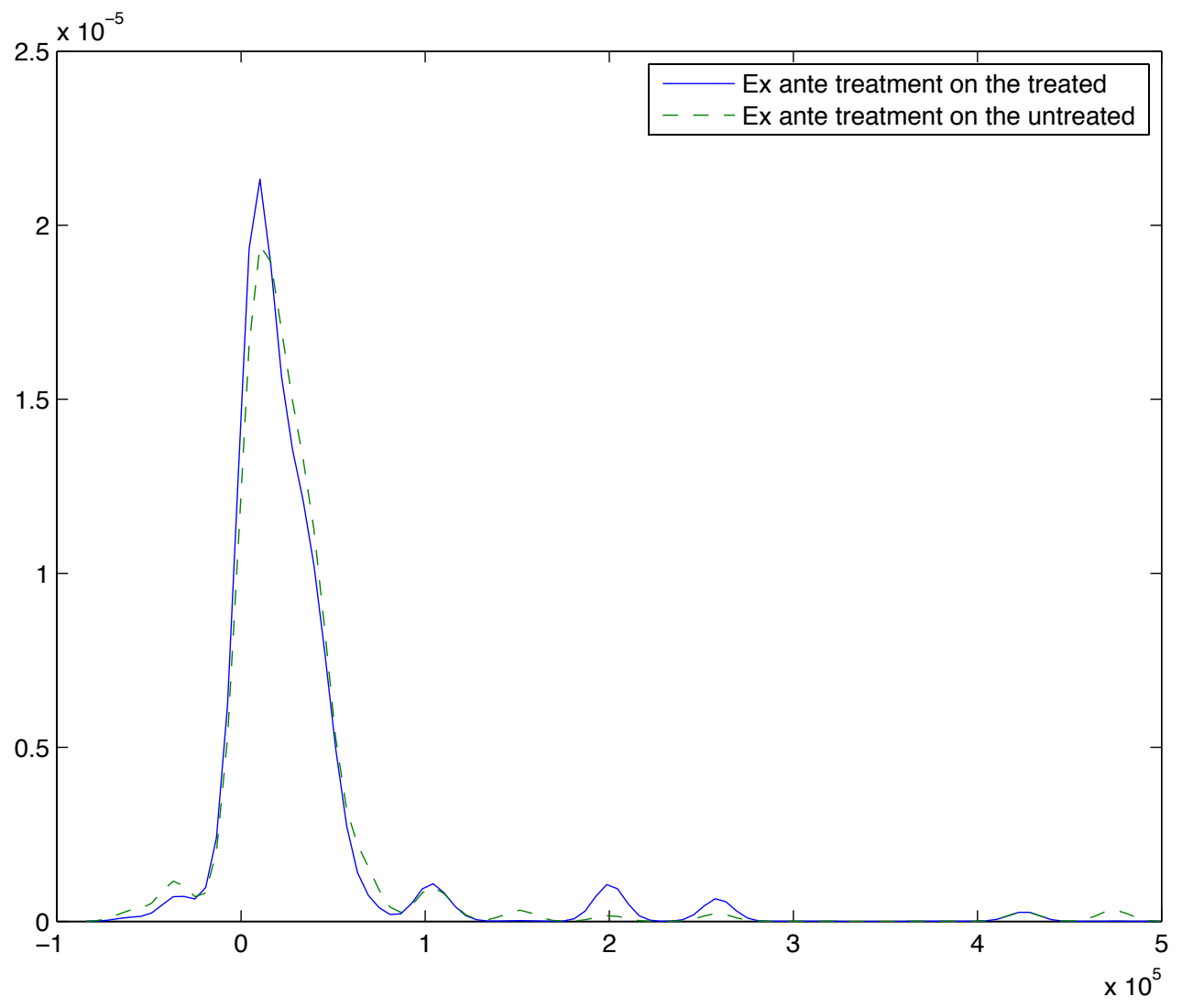

Figure 2: Densities of Ex Ante Treatment Effects: Government 


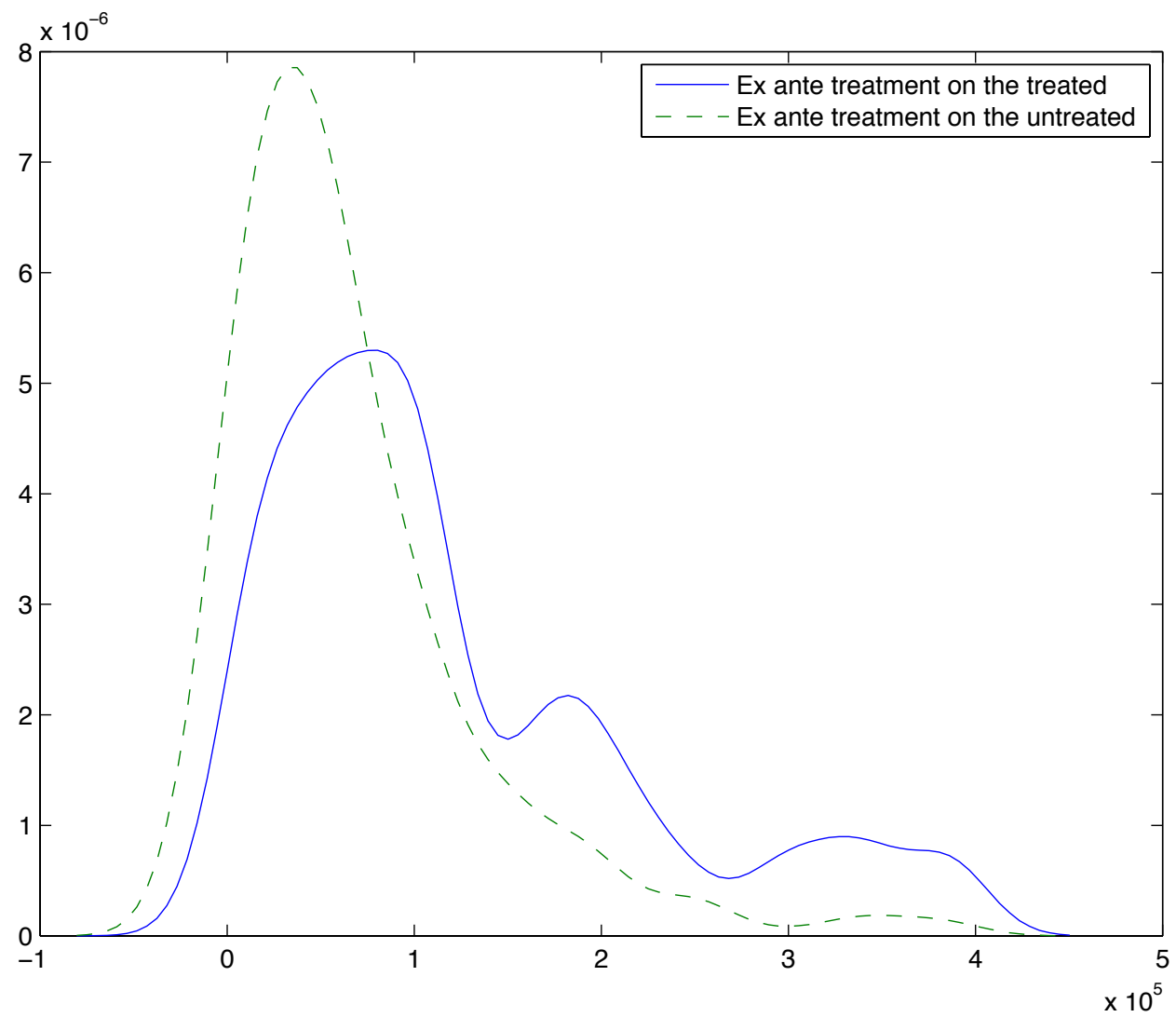

Figure 3: Densities of Ex Ante Treatment Effects: Health 


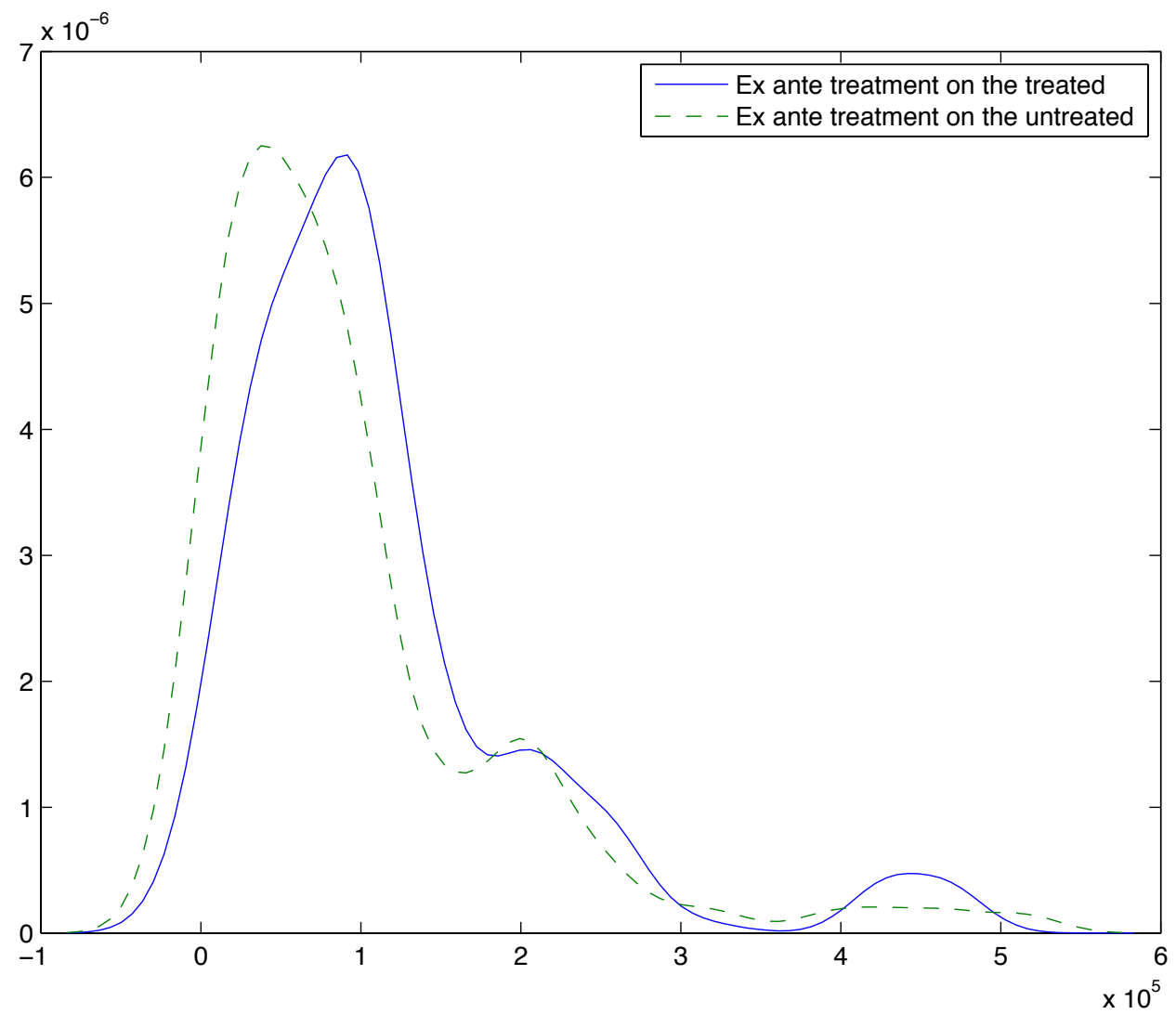

Figure 4: Densities of Ex Ante Treatment Effects: Business 


$$
\widehat{T U T(k \mid j)}:=\frac{\sum_{i} I\left(d_{i}=j\right)\left(1-p_{i j k}\right)\left[w_{i j k}-w_{i j 1}\right]}{\sum_{i} I\left(d_{i}=j\right)\left(1-p_{i j k}\right)}
$$

Given that we also elicit the subjective expectations for counterfactual majors, we can estimate the ex ante treatment effects for those who did not choose major $j$ by replacing $I\left(d_{i}=j\right)$ with $I\left(d_{i} \neq j\right)$.

In Table 8, we present the treatment effect parameters conditional on students' chosen majors. There is a substantial amount of heterogeneity in the expected earnings premium for a given occupation across majors. Notably, Natural Science majors expect on average a $\$ 136,450$ premium for a Health career relative to Education, which is more than five times larger than the $\$ 24,660$ premium expected by Public Policy majors who anticipate to enter this type of occupation. Examining some of the other average ex ante returns, Economics majors have the highest premium for Business occupations, while Engineering and Natural Science majors have the highest premia for Science careers. Overall, these patterns provide evidence of complementarities between majors and occupations. In particular, the majoroccupation pairs that are typically thought of as being closely related to one another - such as Economics and Business, Science and Health, as well as Engineering or Natural Science and Science occupations - do have the highest premia. While these results are consistent with the accumulation of occupation-specific human capital within each major, they are also consistent with a form of selectivity in choice of major, whereby individuals who expect to be more productive in Health are more likely to choose a Science major.

As can be seen in Table 8, ex ante treatment effects on the untreated by student's major generally are lower than the treatment effects on the treated, similar to the results obtained without conditioning on the major (Table 7). There are, however, a couple of exceptions. For instance, ex ante returns to Science careers are higher for the untreated in Social Science majors, while ex ante returns to Government careers are higher for the untreated in the Humanities and Social Sciences. The differences between the ex ante treatment effects on the treated and the ex ante treatment effects on the untreated effects provide, for each major, a measure of the importance of selection on the expected returns to each occupation. For a majority of occupation-major pairs, this difference is positive, consistent with positive sorting on expected earnings in different occupations, but the differences tend to be quantitatively small. Notable exceptions include Legal careers for Social Sciences majors, where selection explains more than $40 \%$ of the expected premium among the treated, as well as Government careers for Science majors, where selection accounts for around half of the expected premium.

Finally, Table 9 provides estimates of the three ex ante treatment effects by counterfactual major. The treatment effects on the treated are again generally larger than the treatment effects on the untreated. It is worth noting that these ex ante treatment effects also exhibit 
a substantial degree of heterogeneity across majors. Notably, expected premia for Business careers are higher for Economics majors, while returns to Science careers are higher for Engineering and Natural Science majors. The fact that these types of complementarities between majors and occupations still hold when focusing on the majors which were not chosen by the individuals points to the accumulation of occupation-specific human capital within majors. ${ }^{21}$

\section{An estimable occupational choice model using sub- jective expectations data}

In this section we layout a model of occupational choice that can be estimated with elicited data on expected earnings in each occupation and expected probabilities of choosing alternative occupations. The key purpose of this framework is to provide a link between subjective expectations and preferences for occupations, which will allow us to estimate the labor supply elasticities for particular occupations along with the preferences over the different occupation-major combinations. In this model, the choice of an occupation is characterized in three stages. First, an individual enrolls in a given college major. Second, upon completing one's major, the individual decides whether or not to acquire more information about the value of a set of particular occupations. Finally, after receiving this information about selected occupations, the individual makes a one-time decision regarding his occupation.

\subsection{Choice of occupations}

We begin by examining the last decision, namely the choice of occupation conditional on graduating from college in a given major and having paid the information cost for a subset of the occupations. This information cost can be thought of as the cost of applying or qualifying for an occupation, such as the costs of taking the Bar exam or acquiring certification for a medical occupation. Let $v_{i j k}$ denote the expected present value of lifetime utility for individual $i$ from choosing occupation $k$ conditional on major $j$, prior to the acquisition of this occupation-specific information. Individuals form their subjective expectations regarding the probabilities of entering different careers based on these conditional value functions. The new information consists of a vector of shocks, or innovations, $\epsilon_{i j k}$, that vary at the individual-

\footnotetext{
${ }^{21}$ See also Kinsler and Pavan (2014) on the importance of major-specific human capital. They find, using data from the Baccalaureate and Beyond Longitudinal Study, that individuals have higher wages when working in an occupation related to one's field of study compared to working in non-related occupations.
} 
Table 8: Ex Ante Treatment Effects of Occupations by Chosen Major (Annual Earnings, in dollars)

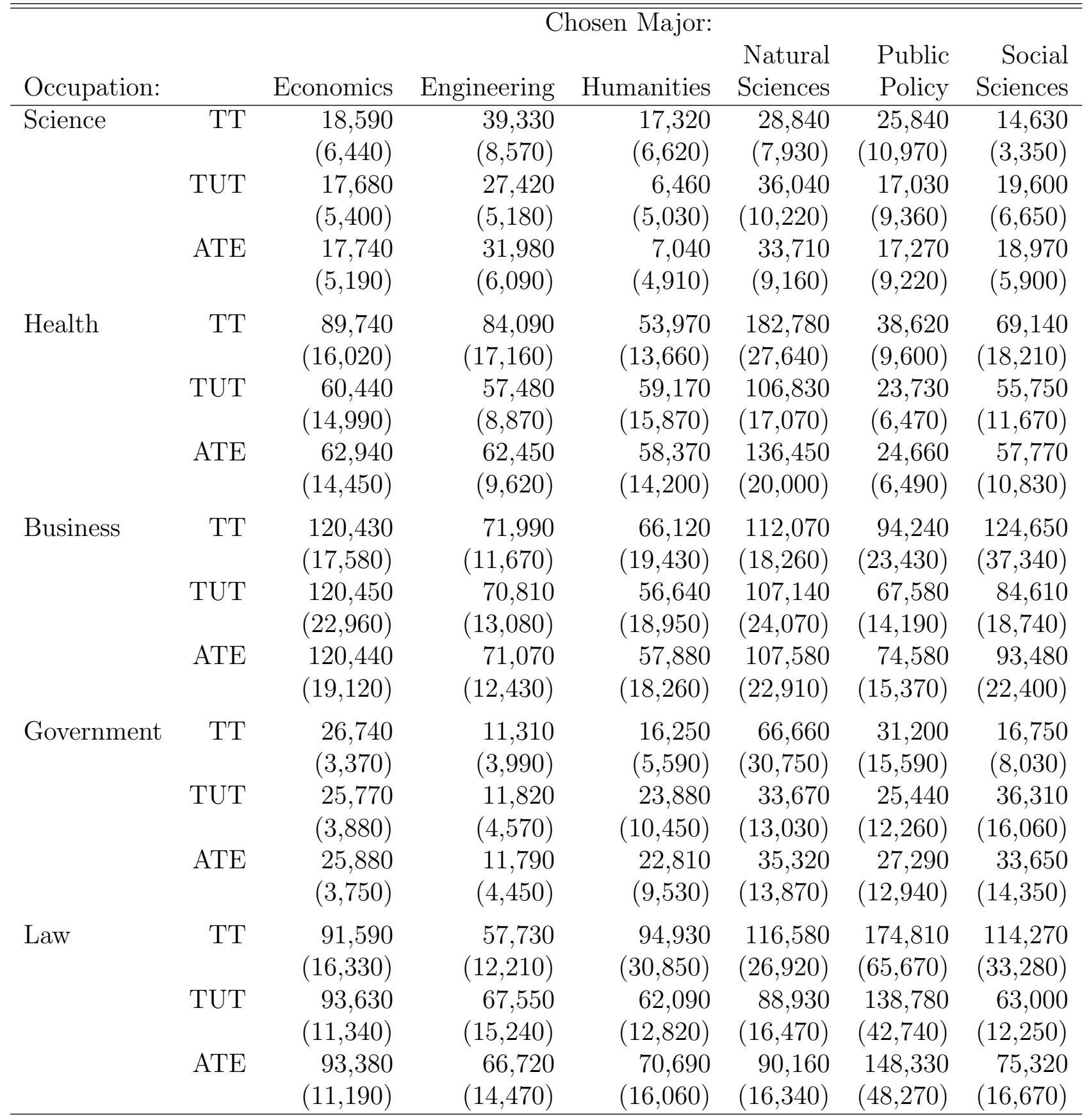

Note: Standard errors are reported in parentheses. 
Table 9: Ex Ante Treatment Effects of Occupations by Counterfactual Major (Annual Earnings, in dollars)

\begin{tabular}{|c|c|c|c|c|c|c|c|}
\hline \multirow{3}{*}{ Occupation: } & \multicolumn{7}{|c|}{ Counterfactual Major: } \\
\hline & & \multirow[b]{2}{*}{ Economics } & \multirow{4}{*}{$\begin{array}{r}\text { Engineering } \\
45,970 \\
(4,600)\end{array}$} & \multirow{4}{*}{$\begin{array}{r}\text { Humanities } \\
19,250 \\
(5,880)\end{array}$} & \multirow{2}{*}{$\begin{array}{l}\text { Natural } \\
\text { Sciences }\end{array}$} & \multirow{2}{*}{$\begin{array}{l}\text { Public } \\
\text { Policy }\end{array}$} & \multirow{2}{*}{$\begin{array}{r}\text { Social } \\
\text { Sciences }\end{array}$} \\
\hline & & & & & & & \\
\hline \multirow[t]{6}{*}{ Science } & $\mathrm{TT}$ & 6,660 & & & 44,130 & 18,530 & 12,060 \\
\hline & & $(5,410)$ & & & $(9,220)$ & $(3,160)$ & $(2,660)$ \\
\hline & TUT & 10,340 & 47,350 & 10,380 & 33,030 & 17,270 & 13,710 \\
\hline & & $(6,470)$ & $(5,650)$ & $(3,050)$ & $(4,080)$ & $(3,320)$ & $(3,180)$ \\
\hline & ATE & 10,130 & 46,790 & 11,080 & 36,910 & 17,340 & 13,560 \\
\hline & & $(6,340)$ & $(4,640)$ & $(3,150)$ & $(5,280)$ & $(3,170)$ & $(2,950)$ \\
\hline \multirow[t]{6}{*}{ Health } & TT & 63,330 & 108,620 & 88,130 & 87,000 & 73,350 & 74,080 \\
\hline & & $(12,110)$ & $(14,020)$ & $(13,400)$ & $(7,890)$ & $(11,010)$ & $(11,090)$ \\
\hline & TUT & 49,950 & 77,180 & 51,290 & 78,230 & 57,630 & 51,950 \\
\hline & & $(8,810)$ & $(7,300)$ & $(7,030)$ & $(7,840)$ & $(7,060)$ & $(7,070)$ \\
\hline & ATE & 50,990 & 83,570 & 55,650 & 80,930 & 59,610 & 55,170 \\
\hline & & $(8,600)$ & $(7,880)$ & $(7,200)$ & $(7,340)$ & $(7,060)$ & $(7,240)$ \\
\hline \multirow{6}{*}{ Business } & TT & 144,000 & 88,120 & 67,360 & 62,780 & 100,270 & 94,280 \\
\hline & & $(21,230)$ & $(11,360)$ & $(7,400)$ & $(7,100)$ & $(23,610)$ & $(12,300)$ \\
\hline & TUT & 100,030 & 80,000 & 58,280 & 56,940 & 84,210 & 63,420 \\
\hline & & $(14,200)$ & $(8,620)$ & $(7,180)$ & $(6,050)$ & $(8,970)$ & $(6,840)$ \\
\hline & ATE & 121,780 & 81,490 & 60,540 & 57,720 & 87,800 & 71,200 \\
\hline & & $(16,430)$ & $(8,350)$ & $(6,460)$ & $(5,900)$ & $(10,500)$ & $(7,210)$ \\
\hline \multirow[t]{6}{*}{ Government } & TT & 20,160 & 28,550 & 24,370 & 24,900 & 50,240 & 34,370 \\
\hline & & & & $(8,540)$ & $(8,390)$ & $(20,560)$ & $(12,510)$ \\
\hline & TUT & 24,450 & 25,160 & 19,380 & 18,860 & 35,450 & 20,230 \\
\hline & & $(7,560)$ & $(4,500)$ & $(4,070)$ & $(3,320)$ & $(7,050)$ & $(2,940)$ \\
\hline & ATE & 23,720 & 25,440 & 20,130 & 19,340 & 40,180 & 23,120 \\
\hline & & $(7,520)$ & $(4,500)$ & $(4,380)$ & $(3,660)$ & $(9,100)$ & $(4,700)$ \\
\hline \multirow[t]{6}{*}{ Law } & TT & 88,460 & 111,330 & 78,760 & 80,020 & 78,150 & 78,460 \\
\hline & & $(19,520)$ & $(50,810)$ & $(9,940)$ & $(17,310)$ & $(6,670)$ & $(9,210)$ \\
\hline & TUT & 78,670 & 98,810 & 79,390 & 68,760 & 87,610 & 82,880 \\
\hline & & $(10,430)$ & $(29,280)$ & $(6,650)$ & $(6,300)$ & $(7,940)$ & $(6,750)$ \\
\hline & ATE & 79,960 & 99,600 & 79,280 & 69,580 & 85,790 & 82,080 \\
\hline & & $(10,400)$ & $(30,400)$ & $(6,770)$ & $(6,750)$ & $(7,290)$ & $(6,570)$ \\
\hline
\end{tabular}

Note: Standard errors are reported in parentheses. 
major-occupation level. For any given major $j$, we assume that the $\epsilon_{i j k}$ 's are independent draws from a standard Type 1 Extreme Value distribution. After choosing a major and graduating from college, these information shocks are realized for the subset of occupations where the individual has paid for the new information and the individual proceeds to choose an occupation. An individual who chose major $j$ then chooses his occupation $k^{*}$ according to:

$$
k^{*}=\arg \max _{k \in K_{i j}^{*}}\left(v_{i j k}+\epsilon_{i j k}\right)
$$

where $K_{i j}^{*}$ is the set of occupations where the individual has paid for the new information conditional on graduating from major $j$. We will discuss the decision to acquire more information about particular occupations in Section 5.3.

\subsection{Using subjective probabilities to characterize preferences for occupations}

Individuals' self-reports of the probabilities of choosing particular occupations, i.e., the $p_{i j k}$ 's, can be used to recover their expected utilities up to a reference alternative. To see this, first consider the case where it is optimal for the individual to pay the informational cost for all possible occupations, conditional on major $j$. With the Type 1 Extreme Value assumption on the $\epsilon_{i j k}$ 's, we can recover the difference in conditional value functions $\left(v_{i j k}-v_{i j 1}\right)$ by inverting the choice probabilities following Hotz and Miller (1993) and Berry (1994):

$$
\begin{aligned}
\Delta \ln p_{i j k} & :=\ln \left(p_{i j k}\right)-\ln \left(p_{i j 1}\right) \\
& =v_{i j k}-v_{i j 1} .
\end{aligned}
$$

In order to tell apart the role played by ex ante returns versus preferences, we need to impose some structure on the value functions. Specifically, we assume that the conditional value functions, for any given major $j$ and occupation $k$, can be written as follows:

$$
v_{i j k}=\alpha_{i k}+\delta_{j k}+\psi_{w} \ln w_{i j k}+\eta_{i j k}
$$

where $\alpha_{i k}$ is the preference individual $i$ has for occupation $k, \delta_{j k}$ captures the average complementarity of preferences between major $j$ and occupation $k, w_{i j k}$ is the expected earnings elicited from $i$ under choices $\{j, k\}$, and $\eta_{i j k}$ is a preference term for occupation $k$, conditional on major $j$, which is assumed to be randomly distributed in the population and uncorrelated with $\ln w_{i j k}$ or $\alpha_{i k} \cdot{ }^{22}$ Similar to Arcidiacono $(2004,2005)$, the value functions are assumed to

\footnotetext{
${ }^{22}$ In practice, monetary or psychic costs of schooling associated with the occupations which typically
} 
depend on future labor market outcomes through the logarithm of the expected earnings. ${ }^{23}$ Taking the difference with respect to the baseline occupation, it follows that:

$$
\begin{aligned}
\Delta \ln p_{i j k} & =\left(\alpha_{i k}-\alpha_{i 1}\right)+\left(\delta_{j k}-\delta_{j 1}\right)+\psi_{w}\left(\ln w_{i j k}-\ln w_{i j 1}\right)+\left(\eta_{i j k}-\eta_{i j 1}\right) \\
& =g\left(\Delta \ln w_{i j k}, \Delta \alpha_{i k}, \Delta \delta_{j k}, \psi_{w}\right)+\zeta_{i j k}
\end{aligned}
$$

where $\Delta \ln w_{i j k}:=\ln w_{i j k}-\ln w_{i j 1}, \Delta \alpha_{i k}:=\alpha_{i k}-\alpha_{i 1}, \Delta \delta_{j k}:=\delta_{j k}-\delta_{j 1}, g\left(\Delta \ln w_{i j k}, \Delta \alpha_{i k}, \Delta \delta_{j k}, \psi_{w}\right):=$ $\Delta \alpha_{i k}+\Delta \delta_{j k}+\psi_{w} \Delta \ln w_{i j k}$ and $\zeta_{i j k}:=\eta_{i j k}-\eta_{i j 1}$.

If all of the elicited probabilities are strictly bounded between zero and one, then the estimation of the parameters in (4.4) is straightforward since we observe, for each individual in the sample, the elicited probabilities, $p_{i j k}$, and expected future earnings, $w_{i j k}$, for all occupation-major pairs $(k, j)$. Variation across majors in occupation-specific subjective probabilities and expected earnings plays a key role in telling apart ex ante returns and preferences, similar to the longitudinal variation used by Wiswall and Zafar (2014) in the context of college major choices. However, if any $p_{i j k}$ 's are zero, as is the case in our data, we have to account for the selectivity of this event. It is important to do so since those who report a zero probability for a given major-occupation pair presumably attach a low value to this alternative. In the next section, we characterize this process in terms of individuals choosing whether or not to acquire more information before entering an occupation.

\subsection{Decision to acquire information about occupations}

We now consider the information acquisition stage of the occupational choice model. Given that the information shocks $\epsilon_{i j k}$ are assumed to have continuous support over the real line, the subjective probabilities would never be zero if information was costless to acquire. In fact, as summarized in Table 4, there is a significant share of zero probabilities. To reconcile our model with the data, we assume that information about occupations is costly and individuals may choose not to bother acquiring it for some occupations in which case they report that they would not enter such occupations. We develop this logic below and what we can learn about the costs of acquiring information about occupations.

require an advanced degree, such as Law, would also be captured by these preference terms. Therefore, it seems likely that our empirical strategy will lead to underestimates of the true preferences for those specific occupations.

${ }^{23}$ While forward-looking individuals should consider the present value of lifetime earnings associated with each occupation, in practice we only observe the expected earnings ten years after graduation. However, we show in Appendix A that, under some plausible assumptions on the discount factor, worklife duration and earnings growth, the earnings ten years out are, up to a multiplicative constant, a reasonably good approximation of the present value of lifetime earnings. 
We assume that the decision to acquire information depends on expectations of the maximal utility associated with different choice sets. Given the Type-1 Extreme Value assumptions regarding the distribution of the $\epsilon$ 's, it follows from McFadden (1978) that the expected maximum utility for any choice set $K$, denoted by $V_{i j}^{(K)}$, can be written as:

$$
V_{i j}^{(K)}=\ln \left[\sum_{k \in K} \exp \left(v_{i j k}\right)\right]+\gamma
$$

where $\gamma$ is Euler's constant. Denote $\{k(1), k(2), \ldots, k(6)\}$ the occupation indices reordered such that $v_{i j k(1)}$ is the highest payoff (prior to the new information), $v_{i j k(2)}$ the next highest payoff, etc.. Let $c$ denote the utility cost of obtaining information on a particular occupation, which for simplicity is supposed to be constant across individuals, occupations and majors. Individuals will choose to obtain this information only if the expected utility gain exceeds the cost of acquiring it. Thus, individual $i$ will choose to acquire information on the occupation with the $m^{t h}$ highest expected payoff, $k(m)$, so long as:

$$
\begin{aligned}
m c-(m-1) c & \leq \ln \left(\sum_{\ell=1}^{m} \exp \left(v_{i j k(\ell)}\right)\right)-\ln \left(\sum_{\ell=1}^{m-1} \exp \left(v_{i j k(\ell)}\right)\right) \\
c & \leq \ln \left(\frac{\sum_{\ell=1}^{m} \exp \left(v_{i j k(\ell)}\right)}{\sum_{\ell=1}^{m-1} \exp \left(v_{i j k(\ell)}\right)}\right)=-\ln \left(1-p_{i j k(m)}\right) .
\end{aligned}
$$

where $p_{i j k(m)}$ denotes the probability of choosing occupation $k(m)$ (given major $j$ ) among the set of occupations $\{k(1), k(2), \ldots, k(m)\}$. It follows that $K_{i j}^{*}$, defined as individual $i$ 's choice set of occupations for major $j$, consists of the occupations for which condition (4.6) holds, i.e., $K_{i j}^{*}:=\left\{k(1), k(2), \ldots, k\left(m_{i j}^{*}\right)\right\}$, where $k\left(m_{i j}^{*}\right)$ is the last occupation in the value-ordered sequence of occupations for individual $i$, conditional on major $j$, for which (4.6) holds. It follows from condition (4.6) that $c$ may be consistently estimated by $-\ln (1-\underline{p})$, where $\underline{p}$ denotes the smallest positive self-reported probability of choosing any of the occupations, conditional on any of the majors, that is found in the data. In practice, we choose to estimate $c$ using instead the $10^{\text {th }}$ smallest positive self-reported probability from the sample. The resulting estimator presents the advantage of being less sensitive to outliers, while still being consistent. ${ }^{24}$

\footnotetext{
${ }^{24}$ We also checked the sensitivity of our analysis to the use of the $5^{t h}$ smallest positive self-reported probability. The estimation results were qualitatively, and in most cases quantitatively, similar. These results are available from the authors upon request.
} 


\subsection{Selectivity of elicited zero choice probabilities}

Reports of zero probabilities can not be ignored in estimating the parameters of (4.3) if there are selective differences in preferences across individuals. Those who report zero probabilities are likely to have relatively low valuations for the associated occupation-major pairs. In the following we characterize the selectivity of those zero probabilities using the information acquisition model presented above. ${ }^{25}$

Consider some occupation $k^{\prime}$ that is not in individual $i$ 's choice set, $K_{i j}^{*}$, when he conditions on major $j$. The individual's expected payoff for this occupation did not warrant him bearing the information cost to learn more about this occupation; as a result, the inequality in (4.6) is flipped and given by:

$$
c>-\ln \left(1-p_{i j k^{\prime}}\right)
$$

where, with a slight abuse of notation, $p_{i j k^{\prime}}$ denotes the counterfactual probability of choosing occupation $k^{\prime}$ if that occupation was in the choice set. $p_{i j k^{\prime}}$ is therefore not observed in the data. However, one can express $p_{i j k^{\prime}}$ as a function of the information cost $c$ and the $v_{i j k}$ 's for those occupations for which $i$ reported non-zero choice probabilities. To see this, note that $p_{i j k^{\prime}}$ can be written as the following function of the valuations of occupation $k^{\prime}$ and of the occupations in $K_{i j}^{*}$ for which information was acquired (assuming without loss of generality that the baseline occupation, $k=1$, belongs to the choice set $K_{i j}^{*}$ ):

$$
\begin{aligned}
p_{i j k^{\prime}} & =\frac{\exp \left(v_{i j k^{\prime}}\right)}{\exp \left(v_{i j k^{\prime}}\right)+\sum_{h \in K_{i j}^{*}} \exp \left(v_{i j h}\right)} \\
& =\frac{\exp \left(v_{i j k^{\prime}}-v_{i j 1}\right)}{\exp \left(v_{i j k^{\prime}}-v_{i j 1}\right)+\sum_{h \in K_{i j}^{*}} \exp \left(v_{i j h}-v_{i j 1}\right)} .
\end{aligned}
$$

Substituting the righthand side of (4.8) for $p_{i j k^{\prime}}$ in the inequality in (4.7) and manipulating the resulting inequality, one can express the (relative) valuation for occupation $k^{\prime}, v_{i j k^{\prime}}-v_{i j 1}$,

\footnotetext{
${ }^{25}$ For an alternative approach to dealing with zero choice probabilities using Least Absolute Deviation estimation, see Blass et al. (2010).
} 
in terms of the choice probabilities of occupations in $K_{i j}^{*}$ :

$$
\begin{aligned}
\exp (-c) & \leq\left(\frac{\sum_{h \in K_{i j}^{*}} \exp \left(v_{i j h}-v_{i j 1}\right)}{\exp \left(v_{i j k^{\prime}}-v_{i j 1}\right)+\sum_{h \in K_{i j}^{*}} \exp \left(v_{i j h}-v_{i j 1}\right)}\right) \\
\exp \left(v_{i j k^{\prime}}-v_{i j 1}\right) & \leq \frac{(1-\exp (-c)) \sum_{h \in K_{i j}^{*}} \exp \left(v_{i j h}-v_{i j 1}\right)}{\exp (-c)} \\
v_{i j k^{\prime}}-v_{i j 1} & \leq \ln \left((\exp (c)-1) \sum_{h \in K_{i j}^{*}} \exp \left(v_{i j h}-v_{i j 1}\right)\right) \\
v_{i j k^{\prime}}-v_{i j 1} & \leq \ln \left((\exp (c)-1) \sum_{h \in K_{i j}^{*}} \exp \left(\Delta \ln p_{i j h}\right)\right)=c_{i j}^{*},
\end{aligned}
$$

where the term $c_{i j}^{*}$ in the last line of (4.9) is a function of the non-zero choice probabilities for occupations in $K_{i j}^{*}$ elicited from individual $i$ and the information cost. It follows from (4.9) and the expression for $v_{i j k^{\prime}}-v_{i j 1}$ implied by (4.4) that:

$$
c_{i j}^{*}-g\left(\Delta \ln w_{i j k^{\prime}}, \Delta \alpha_{i k^{\prime}}, \Delta \delta_{j k^{\prime}}, \psi_{w}\right) \geq \zeta_{i j k^{\prime}}
$$

Our model of occupational choice takes the form of a generalized censored regression model, which is estimated via Maximum Likelihood. Assuming that the preference terms $\eta_{i j k}$ are i.i.d., following a Type 1 extreme value distribution with scale parameter $\gamma$ (whose cumulative distribution function is given by $F(x)=e^{-e^{-x / \gamma}}$ ), the residuals $\zeta_{i j k}=\eta_{i j k}-\eta_{i j 1}$ are independent across individuals $i$ 's and majors, but correlated across occupations.

Taking as given the information cost $c$ which has been estimated in a first step, it follows that the likelihood function for the parameters $\theta:=\left\{\left\{\alpha_{i k}\right\}_{i, k}\left\{\delta_{j k}\right\}_{j, k}, \psi_{w}, \gamma\right\}$ takes the form (see Appendix B for a derivation): ${ }^{26}$

$$
\mathcal{L}(\theta)=\prod_{i} \prod_{j} \frac{\left(\left|K_{i j}^{*}\right|-1\right) ! e^{-\frac{u_{i j 2}+u_{i j 3}+\ldots+u_{i j\left|K_{i j}^{*}\right|}}{\gamma}}}{\gamma^{\left|K_{i j}^{*}\right|-1}\left(1+e^{-u_{i j 2} / \gamma}+\ldots+e^{-u_{i j\left|K_{i j}^{*}\right| / \gamma}}+e^{-\omega_{i j\left(\left|K_{i j}^{*}\right|+1\right) / \gamma}}+\ldots+e^{-\omega_{i j 6} / \gamma}\right)^{\left|K_{i j}^{*}\right|}},
$$

where for any given individual $i$ and major $j$ the occupations with non-zero and zero declared probabilities are indexed by $\left\{1,2, \ldots,\left|K_{i j}^{*}\right|\right\}$ and $\left\{\left|K_{i j}^{*}\right|+1, \ldots, 6\right\}$ respectively, denoting by $\left|K_{i j}^{*}\right|$ the number of occupations with non-zero probabilities and after relabeling if neces-

\footnotetext{
${ }^{26}$ The proposed estimator of the information cost $c$ (see Section 4.3) is a fixed-order statistic. This estimator can be shown, under some regularity conditions on the lower tail of the distribution of the choice probabilities $p_{i j k}$, to converge to the truth at a faster than parametric rate (see van der Vaart, 1998, Section 21.4). It follows that $c$ can be treated as known when conducting inference on the parameters $\theta$.
} 
sary. For each occupation $k \in\{2, \ldots, 6\}, k=1$ denoting the baseline occupation, we let $u_{i j k}:=\Delta \ln p_{i j k}-g\left(\Delta \ln w_{i j k}, \Delta \alpha_{i k}, \Delta \delta_{j k}, \psi_{w}\right)$ and $\omega_{i j k}:=c_{i j}^{*}-g\left(\Delta \ln w_{i j k}, \Delta \alpha_{i k}, \Delta \delta_{j k}, \psi_{w}\right) .{ }^{27}$

Finally, it is worth noting that students may have better information about the labor market for some majors than others. In particular, it may be the case that individuals have better information about the labor market related to their own major than in counterfactual majors. Our model can be relaxed to allow for counterfactual majors to have higher variances associated with the information shocks. Absent additional assumptions, discrete choice models are only identified up to a scale parameter. Implicit in (4.4) is a normalization of the scale of the Type 1 extreme value distribution of $\epsilon_{i j k}$ to 1 . With the structure we have placed on (4.4), we can allow for the variance of $\epsilon_{i j k}$ to be different for counterfactual majors, which amounts to substituting in the likelihood (4.11) $\frac{g\left(\Delta \ln w_{i j k}, \Delta \alpha_{i k}, \Delta \delta_{j k}, \psi_{w}\right)}{1+\omega I\left(d_{i}=j\right)}$ and $\frac{\gamma}{1+\omega I\left(d_{i}=j\right)}$ for $g\left(\Delta \ln w_{i j k}, \Delta \alpha_{i k}, \Delta \delta_{j k}, \psi_{w}\right)$ and $\gamma$, respectively. If $\omega$ is greater than zero, then students are less certain about outcomes in counterfactual majors than they are in their own majors.

\section{Results: Occupational choice model}

\subsection{The effects of expected earnings}

Estimates of the earning parameter, $\psi_{w}$, for different specifications of the conditional valuation functions are given in Table 10. Model 3 corresponds to our baseline specification (Equation (4.3)). For each of the specifications, the estimated effect of (log-)expected earnings is positive and statistically significant at any standard significance level. Noteworthy, these results stress the importance of allowing for complementarities of preferences between majors and occupations, with the estimated earning parameters being cut by $40 \%$ after controlling for the occupation-major dummies. ${ }^{28}$

The final column of Table 10 presents estimates when the variance on the new information is allowed to differ between chosen and counterfactual majors, as discussed earlier. The

\footnotetext{
${ }^{27}$ Our framework corresponds to a nonlinear panel data model with fixed effects, where the longitudinal dimension is given by the college majors $j \in\{1, \ldots, 6\}$. It follows that our MLE estimator is in principle subject to the incidental parameter problem (Neyman and Scott, 1948). We investigated this issue using Monte Carlo simulations, which point to fairly small finite sample biases (of the order of 10\%) affecting our parameters of interest. These results are in line with Greene (2004), who provides suggestive evidence for the case of a Tobit model of a very small incidental parameter bias when the number of periods is larger than five.

${ }^{28}$ For all these specifications, the information cost $c$ is estimated in a first step using the $10^{\text {th }}$ smallest positive self-reported probability from the sample. The cost can be expressed in terms of percentage decrease in (expected) earnings ten years after graduation by dividing it by the effect of earnings differentials coefficient $\psi_{w}$, resulting in estimates ranging from $0.7 \%$ (Model 1) to 1.2\% (Model 2).
} 
coefficient estimate for $\omega$ is positive but small, consistent with the log-likelihood and earnings parameter estimate being stable between Columns (3) and (4). Given these results, we focus in the following on Model 3 as our preferred specification.

To quantify the extent to which expected earnings affects occupational choice, we calculate the percentage change in the probability of choosing an occupation given a percentage change in expected earnings, denoted by $e_{i j k}$. The elasticity formula for our specification is (see, e.g., Train, 2003):

$$
e_{i j k}=\left(1-p_{i j k}\right) \psi_{w}
$$

Note that this formula only applies for the intensive margin, that is for those individuals such that the subjective probability $p_{i j k}$ is strictly bounded between 0 and 1 . For those individuals in our sample, the subjective probabilities of entering a given career conditional on a given major range from 0.003 to 0.962 , yielding elasticities from 0.04 to 0.95 for our preferred specification (Model 3). Taking the chosen (or intended) major from the data as given, we can estimate the average elasticity for occupation $k$ using:

$$
\hat{e_{k}}:=\frac{\sum_{i} \sum_{j} I\left(d_{i}=j\right)\left(1-p_{i j k}\right) \widehat{\psi_{w}}}{N}
$$

where $\widehat{\psi_{w}}$ denotes the maximum likelihood estimate of $\psi_{w}\left(\widehat{\psi_{w}}=0.950\right.$ for our preferred specification). These occupation-specific elasticities range from 0.70 (for Business) to 0.86 (for Education), resulting in a mean elasticity across all occupations equal to 0.79 . It is worth noting that these elasticities are sizable, especially in comparison with the very low earnings elasticities which have been found in the literature on college major choices (see, e.g., Beffy et al., 2012, Long et al., 2014, and Wiswall and Zafar, 2014). This further stresses the importance of considering the choice of college major and the choice of occupation as two separate, albeit related, decisions.

\subsection{Preferences for occupations}

Our specification in (4.3) of the value of college major-occupation bundles allows us to recover, from our subjective probabilities and expected earnings data, individual-specific components of non-wage payoffs for occupation $k$ relative to the baseline occupation $\left(\alpha_{i k}-\right.$ $\alpha_{i 1}$ ) along with the average preferences for occupation $k$ relative to the baseline occupation, for any given major $j\left(\delta_{j k}-\delta_{j 1}\right)$. We can express these non-wage components in terms of percentage increase in (expected) earnings ten years after graduation using the effect of 
Table 10: Occupation Choice Model Estimates

\begin{tabular}{lcccc}
\hline \hline & Model 1 & Model 2 & Model 3 & Model 4 \\
\hline Log expected earnings 10 years out $\left(\psi_{w}\right)$ & 1.342 & 0.813 & 0.950 & 0.964 \\
& $(0.066)$ & $(0.057)$ & $(0.038)$ & $(0.013)$ \\
Variance in counterfactual majors $(\omega)$ & - & - & - & 0.066 \\
& - & - & - & $(0.027)$ \\
Occupation dummies & yes & no & no & no \\
Occupation-major dummies & no & yes & yes & yes \\
Individual-occupation dummies & no & no & yes & yes \\
Better information in own major & no & no & no & yes \\
Log-likelihood (000's) & -9.290 & -8.755 & -7.015 & -7.013 \\
\hline
\end{tabular}

Note: Standard errors are reported in parentheses.

earnings differentials coefficient $\psi_{w}$, and we refer to these as compensating differentials. ${ }^{29}$

We first discuss the estimation results for the individual preferences, before turning to the average preferences. Since the mean of $\alpha_{i k}-\alpha_{i 1}$ is zero because of the inclusion of the occupation-major fixed effects $\left(\delta_{j k}\right.$ 's), individual $i$ would have to be compensated an additional $\left(\alpha_{i 1}-\alpha_{i k}\right) / \psi_{w}$ percent increase in earnings (if positive, otherwise would be willing to forego $\left(\alpha_{i k}-\alpha_{i 1}\right) / \psi_{w}$ percent of earnings) to choose occupation $k$ over occupation 1 relative to the average individual, all else equal. ${ }^{30}$ We can then calculate how much those who actually chose major $j$ value different occupations-beyond the value due to the average complementarity of the major-occupation combination-relative to the average individual.

Table 11 gives, for each occupation and major, the median estimated compensating differential $\left(\alpha_{i 1}-\alpha_{i k}\right) / \psi_{w}$, computed across the individuals who chose that particular major. These differentials are reported as the percentage changes in expected earnings ten years out that are required to make the median individual in a particular major indifferent between the two occupations, all else equal. As one can see, individuals in our sample tend to have preferences to avoid education. In particular, the median individual in social sciences or humanities majors strongly prefer any other occupations relative to education. Natural science majors also tend to have strong preferences for business, government and law over education.

Table 12 gives the median absolute deviations (MAD) of the compensating differentials

\footnotetext{
${ }^{29}$ Note that, strictly speaking, these differentials do not correspond to the traditional definition of compensating differentials, which refer to the existence, in a competitive equilibrium, of wage differentials compensating for job amenities (see, e.g., Rosen, 1986). Instead, our measure is best understood as a measure of the (opposite of) willingness-to-pay for non-wage characteristics associated with each occupation-major combination.

${ }^{30}$ Note that 'all else equal' includes the choice of major as majors vary in their non-pecuniary benefits across occupations as picked up by the $\delta_{j k}$ 's.
} 
Table 11: Heterogeneity in Compensating Differentials for Occupations relative to Education, by Chosen Major

\begin{tabular}{lrrrrr}
\hline \hline Chosen & \multicolumn{5}{c}{ Occupation: } \\
Major: & Science & Health & Business & Government & Law \\
\hline Natural Science & $-0.8 \%$ & $-6 \%$ & $-191.1 \%$ & $-167.8 \%$ & $-131.4 \%$ \\
Engineering & $-88.1 \%$ & $-102.3 \%$ & $-107.4 \%$ & $-115.5 \%$ & $-61.7 \%$ \\
Economics & $-78.3 \%$ & $-40.2 \%$ & $-30.4 \%$ & $-42.5 \%$ & $-27.8 \%$ \\
Public Policy & $-113.2 \%$ & $-105.1 \%$ & $-123.9 \%$ & $-76.5 \%$ & $-23.4 \%$ \\
Social Sciences & $-151.9 \%$ & $-114.3 \%$ & $-174.8 \%$ & $-137.3 \%$ & $-37.2 \%$ \\
Humanities & $-123.3 \%$ & $-116 \%$ & $-205.8 \%$ & $-109 \%$ & $-102.4 \%$ \\
\hline
\end{tabular}

Note: Compensating differentials are expressed in terms of (expected) earnings variation.

Table 12: Dispersion of Compensating Differentials and Log Expected Earnings Relative to Education

\begin{tabular}{lrrrrr}
\hline \hline & Science & Health & Business & Government & Law \\
\hline Compensating Differentials (MAD) & 0.99 & 1.09 & 1.21 & 0.84 & 0.83 \\
Log expected earnings (MAD) & 0.22 & 0.38 & 0.34 & 0.21 & 0.34 \\
\hline
\end{tabular}

and of the log expected earnings, for all occupations relative to Education. ${ }^{31}$ The key takeaway from this table is that compensating differentials are much more dispersed than log expected earnings, the ratio of median absolute deviations ranges from 2.4 (Law) to as much as 4.5 (Science). Overall, these results suggest that variation across individuals in non-wage factors plays a key role in explaining occupational choices.

We next examine how preferences for occupations vary across majors, translating our estimates of the $\delta_{j k}$ parameters into percentage increases in earnings. Table 13 reports average compensating differentials for particular occupation-major combinations, again relative to the education occupation. For a given occupation $k$, conditional on major $j$, the average compensating differential is given by: $\frac{\delta_{j 1}-\delta_{j k}}{\psi_{w}}$. Overall, the signs are generally intuitive and the magnitudes of the compensating differentials strengthen the view that non-wage factors are a major determinant of the choice of occupation. For example, an economics major makes working in business so attractive that, on average, individuals would need to make over three times as much in education (or making less than a third of what they would make in business) to be indifferent between the two occupations. Similarly, a science major makes working in a science occupation so attractive that on average individuals would need to make over two and a half times more in education to be indifferent between the two occupations.

\footnotetext{
${ }^{31}$ We choose to use the median absolute deviation as a measure of dispersion here since it is more robust to outliers than the standard deviation.
} 
Finally, the last column of Table 13 reports what the compensating differentials would need to be if we did not account for differences in earnings across occupations. In this case, we estimate a restricted version of the model where $\psi_{w}$ is set equal to 0 , and we use the earnings parameters from our Model 3 to express the preferences in monetary units. Comparing the last two columns of Table 13 then allows use to see the role earnings play in mitigating compensating differentials. As expected, the compensating differentials in the last column are generally higher (in absolute value) than those when earnings are accounted for, consistent with expected earnings in education being substantially lower than in other occupations. In other words, in all cases, not accounting for those earnings differences would make it appear as though education was even more unattractive than it actually is.

\subsection{Non-pecuniary determinants of occupational choice: differ- ences in offer arrival rates?}

Our estimates of the average compensating differentials associated with different occupationmajor combinations are large, especially relative to the expected monetary gains from them. What can explain these large compensating differentials? The most obvious interpretation, which is the one we have been focusing on so far, is that there are non-pecuniary aspects to the choice of occupations. Individuals may simply like certain occupations (e.g., one has "a calling to be a teacher"), and those preferences may vary across college majors (e.g., studying economics makes business more attractive beyond any salary gains). We did not directly measure these possible motives or factors when we elicited information from students about their ex ante valuations of potential occupations, so we cannot directly answer this question.

In this section we explore the possibility that search frictions and differential rates of arrival of job offers across occupations and majors might be another potential explanation for the large compensating differentials. For example, it may be that the subjective probability of working in business tends to be higher for economics majors (relative to other majors) because the arrival rate of offers in the business occupation is higher for economics majors. Below, we illustrate how such differences in offer arrival rates might affect what the above estimates attribute entirely to preference-based compensating differentials.

Consider a simple case where there are two occupations, $k \in\{1,2\}$. Suppose for major $j$ individuals receive one offer per unit of time in occupation 1 compared to two offers in occupation 2. We assume that the difference between the two offers in occupation 2 comes

solely through non-pecuniary shocks, not through income. If each of the non-pecuniary shocks are treated as another Type 1 Extreme Value shock, then the probability of choosing 
Table 13: Average Compensating Differentials by Major-Occupation Pairs Relative to an Occupation in Education

\begin{tabular}{|c|c|c|c|}
\hline Major & Occupation & Model 3 & $\begin{array}{r}\text { Model } 3 \\
\text { w/o Earnings }\end{array}$ \\
\hline Natural & Science & $-266.4 \%$ & $-308.6 \%$ \\
\hline \multirow[t]{4}{*}{ Science } & Health & $-205.4 \%$ & $-286.5 \%$ \\
\hline & Business & $-101.7 \%$ & $-169.2 \%$ \\
\hline & Government & $-67 \%$ & $-100 \%$ \\
\hline & Law & $67.4 \%$ & $-4.5 \%$ \\
\hline \multirow[t]{5}{*}{ Engineering } & Science & $-295.8 \%$ & $-340.7 \%$ \\
\hline & Health & $-170.2 \%$ & $-241.4 \%$ \\
\hline & Business & $-191.1 \%$ & $-266.8 \%$ \\
\hline & Government & $-80.2 \%$ & $-110.4 \%$ \\
\hline & Law & $40.5 \%$ & $-29.4 \%$ \\
\hline \multirow[t]{5}{*}{ Economics } & Science & $-28 \%$ & $-50.4 \%$ \\
\hline & Health & $-22.3 \%$ & $-79.1 \%$ \\
\hline & Business & $-318.7 \%$ & $-412.5 \%$ \\
\hline & Government & $-227.8 \%$ & $-261.8 \%$ \\
\hline & Law & $-75.6 \%$ & $-149.6 \%$ \\
\hline Public & Science & $31.1 \%$ & $1.6 \%$ \\
\hline \multirow[t]{4}{*}{ Policy } & Health & $-45.7 \%$ & $-105.2 \%$ \\
\hline & Business & $-204.4 \%$ & $-281.8 \%$ \\
\hline & Government & $-260 \%$ & $-303.3 \%$ \\
\hline & Law & $-118.6 \%$ & $-201.5 \%$ \\
\hline Social & Science & $37.8 \%$ & $13.4 \%$ \\
\hline \multirow[t]{4}{*}{ Science } & Health & $-5.3 \%$ & $-65.1 \%$ \\
\hline & Business & $-131.8 \%$ & $-204.3 \%$ \\
\hline & Government & $-124.1 \%$ & $-158.8 \%$ \\
\hline & Law & $-14.7 \%$ & $-92 \%$ \\
\hline \multirow[t]{5}{*}{ Humanities } & Science & $113.7 \%$ & $90.4 \%$ \\
\hline & Health & $88.5 \%$ & $25.2 \%$ \\
\hline & Business & $-75.3 \%$ & $-141.2 \%$ \\
\hline & Government & $-48 \%$ & $-84.1 \%$ \\
\hline & Law & $20.9 \%$ & $-55.5 \%$ \\
\hline
\end{tabular}

Note: Compensating differentials are expressed in terms of (expected) earnings variation. 
occupation 2 will be:

$$
p_{i j 2}=\frac{2 \exp \left(v_{i j 2}\right)}{\exp \left(v_{i j 1}\right)+2 \exp \left(v_{i j 2}\right)}=\frac{\exp \left(v_{i j 2}+\ln (2)\right)}{\exp \left(v_{i j 1}\right)+\exp \left(v_{i j 2}+\ln (2)\right)}
$$

Hence, if offer rates for various occupations differ by major, then this will manifest itself as a compensating differential. ${ }^{32}$

While we cannot separate compensating differentials from variation in offer arrival rates, we can say how large differences in offer rates would have to be to explain the average compensating differentials we find for particular major-occupation combinations. Namely, denote $\lambda_{j k}$ as the arrival rate of offers for occupation $k$ conditional on major $j$. We assume that the offers unobserved components are independently drawn from a Type 1 Extreme Value distribution. Allowing for correlation in this component within an occupation category would result in increases in magnitudes of the differences in arrival rates needed to account for the estimated differences in compensating differentials. Hence, one can think of our approach as identifying the minimum amount of differences in occupation-major offer arrival rates that accounts for the estimated compensating differentials. It follows from the derivation above that our estimates of $\left(\delta_{j k}-\delta_{j 1}\right)$ can be transformed into differences in arrival rates using:

$$
\delta_{j k}-\delta_{j 1}=\ln \left(\lambda_{j k}\right)-\ln \left(\lambda_{j 1}\right)
$$

Solving for $\frac{\lambda_{j k}}{\lambda_{j 1}}$ then gives the number of offers in occupation $k$ per offer in education needed to account for the average major-occupation compensating differential $\left(\frac{\delta_{j 1}-\delta_{j k}}{\psi_{w}}\right)$ previously estimated.

Results are presented in Table 14. The differences in job arrival rates needed to fully account for the compensating differentials associated with major-occupation pairings are quite large. For example, natural science majors would have to receive at least 12.6 offers in science occupations and 2.6 offers in business for every one offer in education. In contrast, humanities majors would expect significantly fewer offers in the sciences, 0.3 offer for every offer in education, with twice as many offers in business as in education. Majoring in economics would need to result in 20.6 offers in business for every offer in education to account for the compensating differential associated with the economics-business combination. These results, combined with those in Table 13, suggest that in practice both stories (major-specific preferences and major-specific job offer arrival rates, for each occupation) are likely to play a role. In either event, college majors have a substantial effect on the future labor market

\footnotetext{
${ }^{32}$ Note that variance in earnings from which offers are drawn would also generate a similar result, but would require heterogeneity in the variance across majors. Variance in offered wages would have to be unreasonably different across majors to explain our results.
} 
Table 14: Number of Offers per Offer in Education Necessary to Account for Average Major-Occupation Compensating Differentials

\begin{tabular}{lrrrrr}
\hline \hline & & \multicolumn{5}{c}{ Occupation: } \\
Major: & Science & Health & Business & Government & Law \\
\hline Natural Science & 12.6 & 7 & 2.6 & 1.9 & 0.5 \\
Engineering & 16.6 & 5 & 6.1 & 2.1 & 0.7 \\
Economics & 1.3 & 1.2 & 20.6 & 8.7 & 2.1 \\
Public Policy & 0.7 & 1.5 & 7 & 11.8 & 3.1 \\
Social Science & 0.7 & 1.1 & 3.5 & 3.2 & 1.1 \\
Humanities & 0.3 & 0.4 & 2 & 1.6 & 0.8 \\
\hline
\end{tabular}

Note: Calculations based on estimates of Model 3.

outcomes beyond their impact on earnings.

\section{Conclusion}

This paper investigates the role played by ex ante monetary returns versus preferences in the context of sorting across occupations. To do so, we use elicited beliefs from a sample of male undergraduates at Duke University on the probabilities of working in different occupations as well as on the expected earnings in each of those occupations, ten years after graduation. Importantly, these beliefs were asked not only for the college major the individual chose or intended to choose, but also for all counterfactual majors, thus making it possible to examine the complementarities between majors and occupations, both in terms of earnings and preferences.

The distributions of the ex ante monetary returns (or ex ante treatment effects on earnings) for particular occupations, conditional on each college major, for the overall, treated and untreated subpopulations are directly identified from our subjective expectations data. We find large differences in expected earnings across occupations, with a substantial degree of heterogeneity across individuals. The estimates also suggest that those who place high probabilities on working in particular occupations also tend to expect the greatest monetary returns from those occupations: the treatment on the treated is, for most occupations, significantly higher than the treatment on the untreated. Clear complementarities exist between majors and occupations. For example, expected returns for business careers are highest for economics major, which in turn leads individuals to report higher probabilities of pursuing a business occupation in the (sometimes) hypothetical case that they were an economics major.

We then derive a simple model of occupational choice which provides a link between 
subjective expectations and preferences, making it possible to tell apart the role of expected earnings and non-pecuniary factors in this context. While sorting across occupations is found to be partly driven by the ex ante monetary returns, our estimation results suggest that non-monetary factors play an even larger role in the decision to work in particular occupations. Finally, our results also provide evidence of complementarities between majors and occupations in terms of preferences, and possibly through the existence of differential search frictions across majors. 


\section{References}

Altonji, J., E. Blom, and C. Meghir, "Heterogeneity in Human Capital Investments: High School Curriculum, College Majors, and Careers," Annual Review of Economics, 2012, 4, 185-223.

Antonovics, K. and L. Golan, "Experimentation and Job Choice," Journal of Labor Economics, 2012, 30, 333-366.

Arcidiacono, P., "Affirmative action in higher education: how do admission and financial aid rules affect future earnings?," Econometrica, 2005, 73, 1477-1524.

_ , E. Aucejo, H. Fang, and K. Spenner, "Does Affirmative Action Lead to Mismatch? A New Test and Evidence," Quantitative Economics, 2011, 2, 303-333.

_ , V. J. Hotz, and S. Kang, "Modeling college major choices using elicited measures of expectations and counterfactuals," Journal of Econometrics, 2012, 166, 3-16.

Beffy, M., D. Fougere, and A. Maurel, "Choosing the Field of Studies in Postsecondary Education: Do Expected Earnings Matter?," Review of Economics and Statistics, 2012, 94, 334-347.

Berry, S. T., "Estimating Discrete-Choice Models of Product Differentiation," The RAND Journal of Economics, 1994, 25, 242-262.

Blass, A., S. Lach, and C. Manski, "Using elicited choice probabilities to estimate random utility models: preferences for electricity reliability," International Economic Review, 2010, 51, 421-440.

Carneiro, P.M., K.T. Hansen, and J.J. Heckman, "Estimating Distributions of Treatment Effects with an Application to the Returns to Schooling and Measurement of the Effects of Uncertainty on College Choice," International Economic Review, 2003, 44, 361422.

Cunha, F. and J. J. Heckman, "Identifying and Estimating the Distributions of Ex Post and Ex Ante Returns to Schooling," Labour Economics, 2007, 14, 870-893.

_ and _, "A new framework for the analysis of inequality," Macroeconomic Dynamics, 2008, 12, 315-354.

_, , , and S. Navarro, "Separating uncertainty from heterogeneity in life cycle earnings," Oxford Economic Papers, 2005, 57, 191-261. 
Delavande, A., "Pill, patch, or shot? Subjective expectations and birth control choice," International Economic Review, 2008, 49, 999-1042.

- and B. Zafar, "University Choice: The Role of Expected Earnings, Non-pecuniary Outcomes and Financial Constraints," 2014. Working paper.

D'Haultfoeuille, X. and A. Maurel, "Inference on an Extended Roy Model, with an Application to Schooling Decisions in France," Journal of Econometrics, 2013, 174, 95106.

Dominitz, J. and C. Manski, "Eliciting student expectations of the returns to schooling," Journal of Human Resources, 1996, 19, 408-428.

_ and _, "Using expectations data to study subjective income expectations," Journal of the American Statistical Association, 1997, 92, 855-867.

Eisenhauer, P., J. J. Heckman, and E. Vytlacil, "The generalized Roy model and the cost-benefit analysis of social programs," Forthcoming in the Journal of Political Economy, 2014.

Greene, W., "The behaviour of the maximum likelihood estimator of limited dependent variable models in the presence of fixed effects," Econometrics Journal, 2004, 7, 98-119.

Hotz, V. J. and R. A. Miller, "Conditional Choice Probabilities and the Estimation of Dynamic Models," Review of Economic Studies, 1993, 60, 497-529.

Hurd, M., "Subjective Probabilities in Household Surveys," Annual Review of Economics, $2009,1,543-562$.

- and K. McGarry, "Evaluation of the subjective probabilities of survival in the HRS," Journal of Human Resources, 1995, 30, S268-S292.

_ and _ , "The predictive validity of subjective probabilities of survival," Economic Journal, 2002, 112, 966-985.

Kang, S., "Eliciting expectations and counterfactuals about college major choice: Data Documentation," 2009. Working paper.

Keane, M. and K. I. Wolpin, "The Career Decisions of Young Men," Journal of Political Economy, 1997, 105, 473-522. 
Kinsler, J. and R. Pavan, "Specifity of general human capital: evidence from college major choice," Forthcoming in the Journal of Labor Economics, 2014.

Long, M.C., D. Goldhaber, and N. Huntington-Klein, "Do Students' College Major Choices Reflect Changes in Wages?," 2014. Unpublished.

Manski, C., "Adolescent Econometricians: How Do Youths Infer the Returns to Schooling?," in C.T. Clotfelter and M. Rothschild, eds., Studies of Supply and Demand in Higher Education, Chicago: University of Chicago Press, 1993.

_., "Measuring Expectations," Econometrica, 2004, 72, 1329-1376.

McFadden, D., "Modelling the Choice of Residential Location," in F. Snickars and J. Weibull, eds., Spatial Interaction and Planning Models, Amsterdam: North-Holland, 1978, pp. 75-96.

Miller, R. A., "Job Matching and Occupational Choice," Journal of Political Economy, 1984, 92, 1086-1120.

Neyman, J. and E. L. Scott, "Consistent estimates based on partially consistent observations," Econometrica, 1948, 16, 1-32.

Osman, A., "Occupational choice under credit and information constraints," 2014. Working paper.

Pantano, J. and Y. Zheng, "Using Subjective Expectations Data to Allow for Unobserved Heterogeneity in Hotz-Miller Estimation Strategies," 2013. Working paper.

Reuben, E., M. Wiswall, and B. Zafar, "Preferences and Biases in Educational Choices and Labor Market Expectations: Shrinking the Black Box of Gender," 2013. Working paper.

Rosen, S., "The theory of equalizing differences," in O. Ashenfelter and D. Card, eds., Handbook of Labor Economics, Vol. 1, Elsevier, 1986, pp. 641-692.

Siow, A., "Occupational choice under uncertainty," Econometrica, 1984, 52, 631-645.

Stinebrickner, T. and R. Stinebrickner, "A major in science? Initial beliefs and final outcomes for college major and dropout," Review of Economic Studies, 2014, 81, 426-472.

Train, K., Discrete Choice Methods with Simulation, Cambridge University Press, 2003. 
van der Klaauw, W., "On the use of expectations data in estimating structural dynamic choice models," Journal of Labor Economics, 2012, 30, 521-554.

_ and K. I. Wolpin, "Social security and the retirement and savings behavior of lowincome households," Journal of Econometrics, 2008, 145, 21-42.

van der Vaart, A. W., Asymptotic Statistics, Cambridge, U.K.: Cambridge University Press, 1998.

Wiswall, M. and B. Zafar, "Determinants of college major choice: identification using an information experiment," Forthcoming in the Review of Economic Studies, 2014.

Zafar, B., "How do college students form expectations?," Journal of Labor Economics, 2011, 29, 301-348.

_ , "College major choice and the gender gap," Journal of Human Resources, 2013, 48, $545-595$. 


\section{A Earnings 10 years out as an approximation of the present value of lifetime earnings}

We provide below some sufficient conditions under which earnings ten years after graduation can be used to approximate the present value of lifetime earnings, for any given major and occupation.

Specifically, let $w_{10}$ (respectively $w_{t}$ ) denote the earnings ten years out (resp. $t$ years out), $\beta$ the annual discount factor and $T$ the worklife duration (number of years). We define the approximation error as $\Delta:=\left|w_{10}-\frac{\sum_{t=1}^{T} \beta^{t} w_{t}}{\sum_{t=1}^{T} \beta^{t}}\right|$. Individual, major and occupation subscripts are omitted to save on notations. Assuming that earnings grow at a constant rate $\rho$ $\left(w_{t+1}=w_{t} \exp (\rho)\right)$, it follows that the approximation error can be written as:

$$
\Delta=\left|w_{10}\left(\exp (-10 \rho) \frac{\sum_{t=1}^{T} \beta^{t} \exp (\rho t)}{\sum_{t=1}^{T} \beta^{t}}-1\right)\right|
$$

Setting $\beta=0.9, \rho=3 \%$ and $T=40$ years yields $\frac{\Delta}{w_{10}} \simeq 0.015$. It follows that, under those assumptions, the earnings ten years after graduation are reasonably close to the present value of lifetime earnings, weighted by the sum $\sum_{t=1}^{T} \beta^{t}$. The latter term does not vary across occupations and therefore drops out when taking the difference with respect to the baseline occupation (see Equation(4.4) p.23 in the main text). 


\section{B Occupational choice model: derivation of the likeli- hood}

We derive below the expression of the contribution to the likelihood for a given individual $i$ and major $j$. We omit the subscripts $i$ and $j$ in the following to ease the notational burden. We first derive the likelihood in a simple case with 4 occupations such that the declared probabilities are different from zero for occupations 1,2 and 3 but equal to zero for occupation 4 , and the scale parameter $\gamma$ is set equal to 1 , before turning to the general case. We let $u_{2}:=\Delta \ln p_{2}-g\left(\Delta \ln w_{2}, \Delta \alpha_{2}, \Delta \delta_{2}, \psi_{w}\right)$ and $u_{3}:=\Delta \ln p_{3}-g\left(\Delta \ln w_{3}, \Delta \alpha_{3}, \Delta \delta_{3}, \psi_{w}\right)$, and $\omega_{4}:=c^{*}-g\left(\Delta \ln w_{4}, \Delta \alpha_{4}, \Delta \delta_{4}, \psi_{w}\right)$. The contribution to the likelihood writes:

$$
\begin{aligned}
& l\left(\eta_{2}-\eta_{1}=u_{2}, \eta_{3}-\eta_{1}=u_{3}, \eta_{4}-\eta_{1} \leq \omega_{4}\right)=\int_{-\infty}^{\infty} l\left(\eta_{2}=\eta_{1}+u_{2}, \eta_{3}=\eta_{1}+u_{3}, \eta_{4} \leq \eta_{1}+\omega_{4}\right) l\left(\eta_{1}\right) d \eta_{1} \\
& =\int_{-\infty}^{\infty} e^{-e^{-\eta_{1}}\left(1+e^{-u_{2}}+e^{-u_{3}}+e^{-\omega_{4}}\right)} e^{-3 \eta_{1}} e^{-\left(u_{2}+u_{3}\right)} d \eta_{1}
\end{aligned}
$$

After a change of variable $\left(z:=e^{-\eta_{1}}\left(1+e^{-u_{2}}+e^{-u_{3}}+e^{-\omega_{4}}\right)\right)$, we obtain:

$$
l\left(\eta_{2}-\eta_{1}=u_{2}, \eta_{3}-\eta_{1}=u_{3}, \eta_{4}-\eta_{1} \leq \omega_{4}\right)=\frac{e^{-\left(u_{2}+u_{3}\right)}}{\left(1+e^{-u_{2}}+e^{-u_{3}}+e^{-\omega_{4}}\right)^{3}} \int_{0}^{\infty} z^{2} e^{-z} d z
$$

where the integral on the right hand-side is the gamma function evaluated in $3(\Gamma(3)=2 !=$ 2). It follows that the contribution to the likelihood writes:

$$
l\left(\eta_{2}-\eta_{1}=u_{2}, \eta_{3}-\eta_{1}=u_{3}, \eta_{4}-\eta_{1} \leq \omega_{4}\right)=\frac{2 e^{-\left(u_{2}+u_{3}\right)}}{\left(1+e^{-u_{2}}+e^{-u_{3}}+e^{-\omega_{4}}\right)^{3}}
$$

It is straightforward to extend the derivation above to write the contribution to the likelihood $l$ corresponding to the most general case of an individual and major such that the occupations with non-zero and zero declared probabilities are indexed by $\left\{1,2, \ldots,\left|K^{*}\right|\right\}$ and $\left\{\left|K^{*}\right|+1, \ldots, 6\right\}$ respectively, denoting by $\left|K^{*}\right|$ the number of occupations with non-zero probabilities and after relabeling if necessary:

$$
l=\frac{\left(\left|K^{*}\right|-1\right) ! e^{-\frac{u_{2}+u_{3}+\ldots+u_{\left|K^{*}\right|}}{\gamma}}}{\gamma^{\left|K^{*}\right|-1}\left(1+e^{-u_{2} / \gamma}+\ldots+e^{-u_{\left|K^{*}\right|} / \gamma}+e^{-w_{\left|K^{*}\right|+1} / \gamma}+\ldots+e^{-w_{6} / \gamma}\right)^{\left|K^{*}\right|}}
$$

